\title{
Cafe nudge project: choice architecture for eating and nudging healthy behaviors
}

\author{
Shannon N. Ackerman \\ West Virginia University
}

Follow this and additional works at: https://researchrepository.wvu.edu/etd

\section{Recommended Citation}

Ackerman, Shannon N., "Cafe nudge project: choice architecture for eating and nudging healthy behaviors" (2014). Graduate Theses, Dissertations, and Problem Reports. 182.

https://researchrepository.wvu.edu/etd/182

This Thesis is protected by copyright and/or related rights. It has been brought to you by the The Research Repository @ WVU with permission from the rights-holder(s). You are free to use this Thesis in any way that is permitted by the copyright and related rights legislation that applies to your use. For other uses you must obtain permission from the rights-holder(s) directly, unless additional rights are indicated by a Creative Commons license in the record and/ or on the work itself. This Thesis has been accepted for inclusion in WVU Graduate Theses, Dissertations, and Problem Reports collection by an authorized administrator of The Research Repository @ WVU. For more information, please contact researchrepository@mail.wvu.edu. 


\title{
Café Nudge Project: Choice Architecture for Eating \& Nudging Healthy Behaviors
}

\section{Shannon N. Ackerman}

Thesis submitted to the Davis College of Agriculture, Natural Resources \& Design

at

West Virginia University

in

partial fulfillment of the requirements

for the degree of

Master of Science

in

Nutrition and Food Science

\author{
Melissa Olfert, DrPH, MS, RD, LD, Chair \\ Cheryl Brown, PhD \\ Cecil Pollard, MA \\ Department of Animal \& Nutritional Sciences
}

Morgantown, West Virginia

2014

Keywords: Choice Architecture; Smarter Lunchrooms; Behavioral Economics;

High School Cafeterias

Copyright 2014 Shannon N. Ackerman 


\section{ABSTRACT \\ Café Nudge Project: Choice Architecture for Healthy Eating Behaviors \\ Shannon N. Ackerman}

The objective of the Café Nudge Project was to assess the cafeteria environment and the flow of students through the lunch-line to determine characteristics that could be enhanced to encourage healthy food choices in three Appalachian high schools. The Center for Behavioral Economics and Child Nutrition Program (BEN Center) has collectively conducted prior research on this topic and has coined the term "Smarter Lunchrooms Movement" for improving cafeteria environments. These improvements included increased fresh fruit and vegetable consumption, increased consumption of low-fat white milk, and decreased consumption of high-fat and highcalorie foods. This study was a two-part observation. In the first part, the cafeteria was videotaped to observe how students move through the serving areas. Each site was given three different scores when referring to the video component of the project. In the second part, an assessment tool was created from adapting research from the BEN Center on Smarter

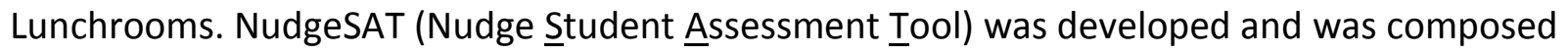
of 6 different scoring categories that according to BEN make up a smarter lunchroom. Eight components using auditor interpretation of the exterior, hot serving area, cold serving area, salad bar, beverage area, payment station, dining area and grab-n-go (only 2 sites had this option) were identified with a score (higher score equals more healthier components offered). High School (HS) \#1 earned 73/128 points (57\%), High School \#2 earned 69/128 points (54\%) and High School \#3 earned 53/102 (52\%). Since High School \#3 did not have a grab and go option the final score was out of 102. Each school had a summary report based on 
recommendations identified for improvement to score higher. HS \#1 and HS \#2 received low scores in the serving areas of the cafeteria, in the dining area, and the grab and go section. HS \#2 also received low scores in the beverage and payment stations. HS \#3 received a much lower score compared to HS \#1 and HS \#2 because it did not have a grab and go section. The NudgeSAT evaluation tool to understand choice architecture is one more novel way to assess the lunchroom environment to encourage smarter lunchroom choices. The long-term impact of adjusting small changes in a cafeteria environment may translate into healthier food choices by students, which leads to improvement in nutritional status and health profiles of students utilizing the National School Lunch Program. 


\section{ACKNOWLEDGEMENTS}

First I would like to thank Dr. Melissa Olfert, for providing me with the opportunity to work on the United States Department of Agriculture Observational Research Study, titled CAfé Nudge Project: Choice Architecture for Eating \& Nudging Healthy Behaviors. I truly appreciate her time and encouragement over the past two years. I would also like to thank Dr. Cheryl Brown for providing her input and support throughout the study. Next I would like to thank Cecil Pollard for being on my committee and providing his expertise whenever needed. I would also like to thank Dr. Emily Murphy for revising many components of the thesis document as well as providing a lot of support over the past two years. I would also like to thank the students who participated as Café Nudge research team during the 2013 spring semester. I really appreciate the time the team dedicated to the project. In closing, I would like to thank all the stakeholders that contributed to the project. Specifically, Dr. Frank Devano, Karen Ghiardi, and all the school principals and cafeteria staff, without them this project would not have been possible. Also, thank you to my friends and family for all the support. 


\section{TABLE OF CONTENTS}

ABSTRACT

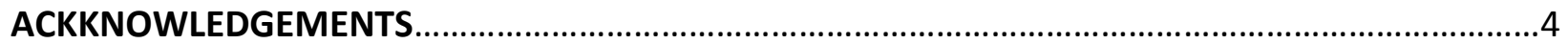

APPENDICES

LIST OF TABLES

LIST OF FIGURES

LIST OF GRAPHS.

ABBREVIATIONS

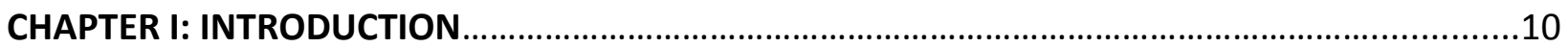

The Cornell Center for Behavioral Economics in Child Nutrition Program..........................10

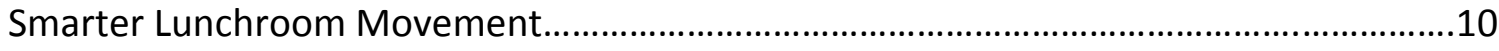

Nudge Student Assessment Tool.......................................................................................11

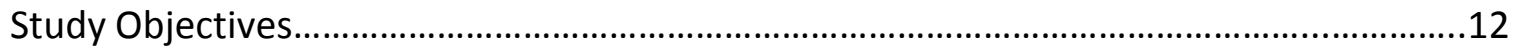

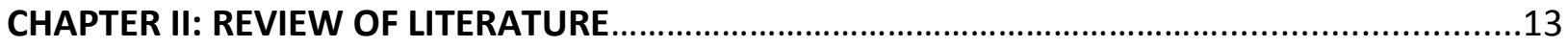

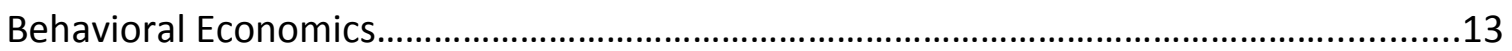

Application of Behavioral Economics in Cafeteria Environments.....................................15

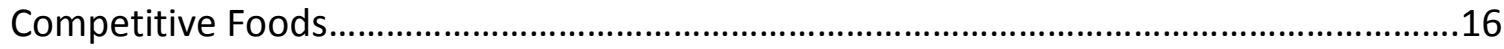

National School Lunch Program Policy.........................................................................18

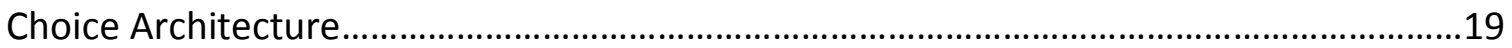

Smarter Lunchroom Movement................................................................................20

Visibility and Availability of Fresh Fruits and Vegetables..................................................21

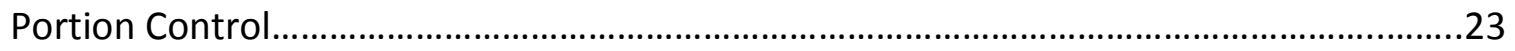




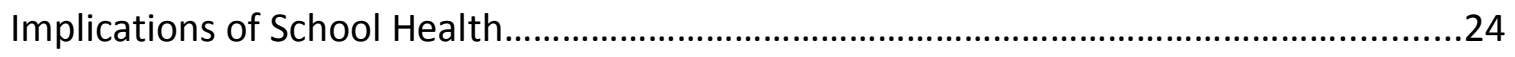

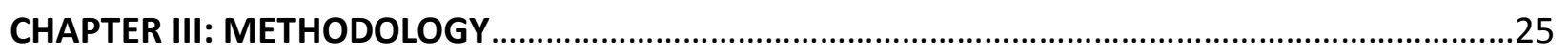

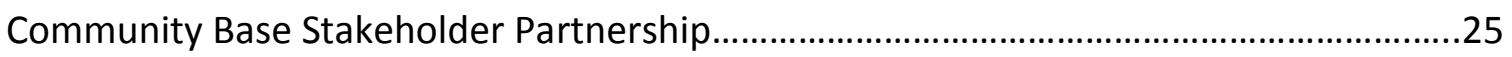

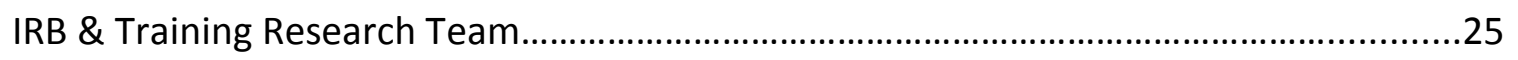

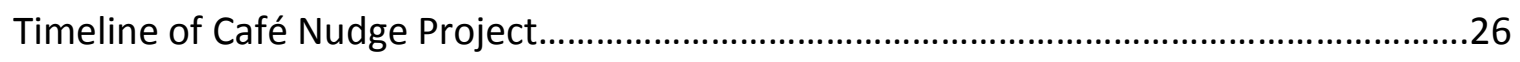

Part 1 - NudgeSAT Development \& Application............................................................27

Part 2 - Video Observation.......................................................................................... 30

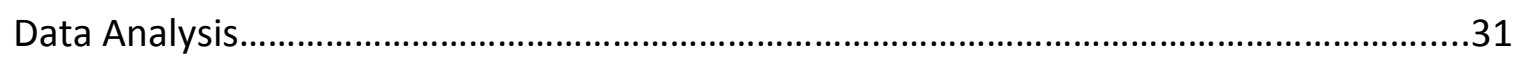

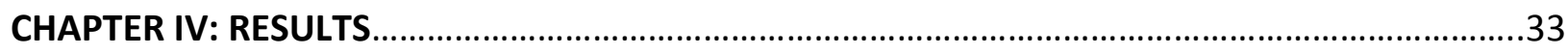

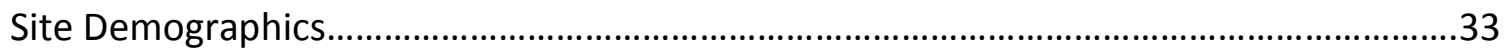

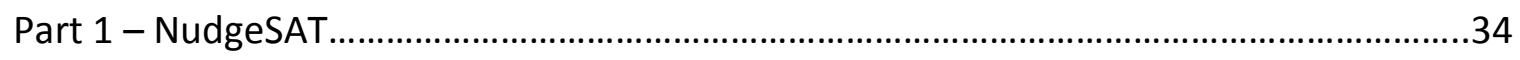

Part 2 - Video Observation \& Post-Site -Visit Questions................................................35

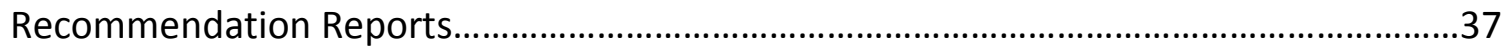

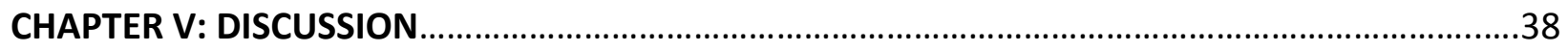

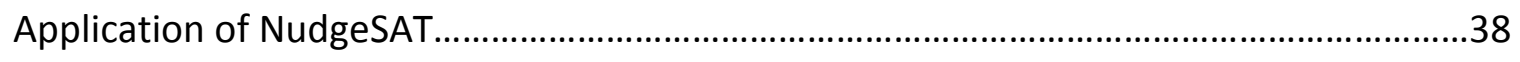

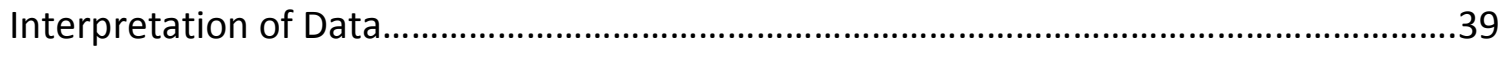

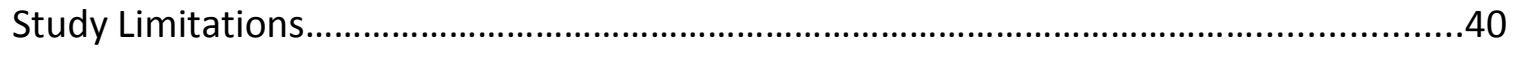

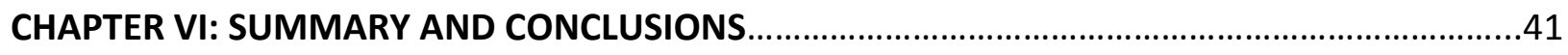

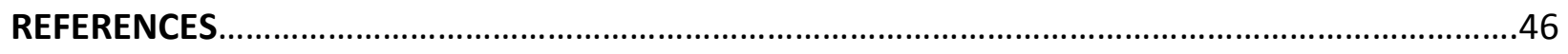

APPENDICES

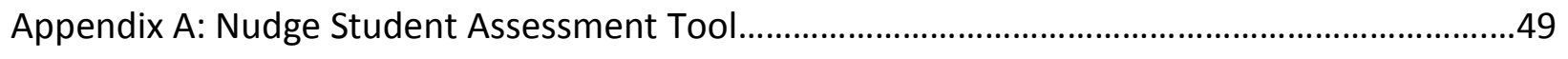

Appendix B: Video Assessment Tool.....................................................................................63 


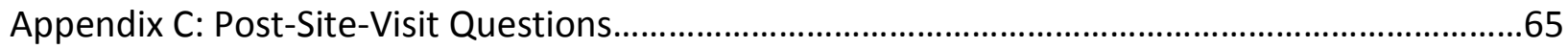

Appendix D: Site \#1 Recommendation Report........................................................................66

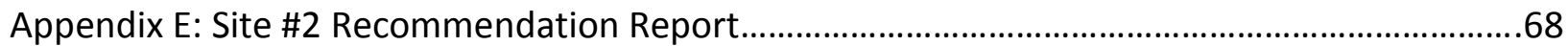

Appendix F: Site \#3 Recommendation Report...............................................................................70 


\section{LIST OF TABLES}

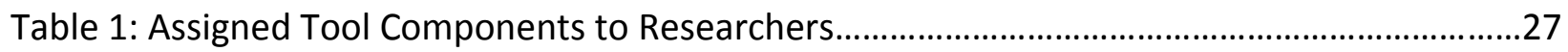

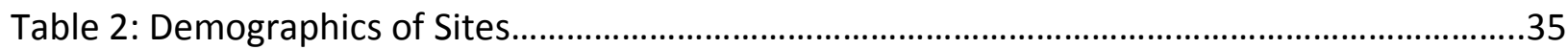

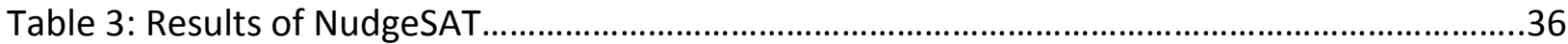

\section{LIST OF FIGURES}

Figure 1: Community-Based Participatory Research Approach.................................................26

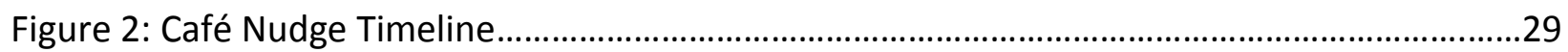

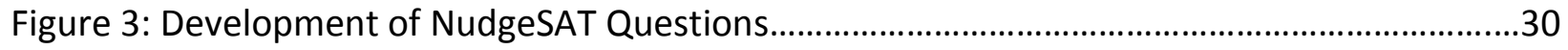

\section{LIST OF GRAPHS}

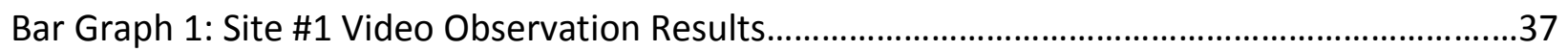

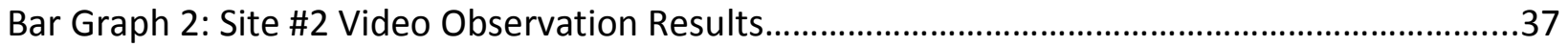

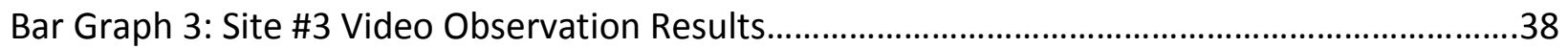




\section{LIST OF ABBREVIATIONS}

BEN Center - Cornell Center for Behavioral Economics in Child Nutrition Program

CBPR - Community-Based Participatory Research

CDC - Centers for Disease Control and Prevention

FNS - Food and Nutrition Service

IRB - Institutional Review Board

BOE -Board of Education

NSLP - National School Lunch Program

NudgeSAT - Nudge Student Assessment Tool

SNDA-III - School Nutrition Dietary Assessment Study III

TACOS - Trying Alternative Cafeteria Options in Schools

USDA - United States Department of Agriculture

WV - West Virginia

WVU - West Virginia University 


\section{CHAPTER I}

\section{INTRODUCTION}

\section{The Center for Behavioral Economics and Child Nutrition Program (The BEN Center)}

In 2010, the Centers for Disease Control and Prevention (CDC) reported that $30 \%$ of WV adolescents in grades 9-12 were considered to be overweight or obese. Meals and snacks consumed at school make up the majority of children's total daily nutrient consumption. Middle and high schoolers are allowed food choice during school mealtimes; however, students are making less than optimal food choices. There have been many studies that try to alter adolescents' food choices. Specifically, the Center for Behavioral Economics and Child Nutrition Program (The BEN Center) at Cornell University has been putting important emphasis on this type of research to further understand cafeteria dynamics. Most of the research produced by the BEN Center uses a behavioral economics approach, which looks at decision-making on economic practices. This theory was applied to choices made by students in school cafeterias. Another term that is used throughout this research is choice architecture. Choice architecture has a major effect on people's decision making. "Choice architects can preserve freedom of choice while also nudging people in directions that will improve their lives." ${ }^{15}$ The ultimate goal is to create an environment that nudges students toward healthy food choices.

\section{Smarter Lunchrooms Movement}

The BEN Center has conducted prior research on nudging students towards healthier options and has coined the term Smarter Lunchrooms Movement for improving the high school cafeteria environment. The BEN Center has also created six smarter lunchroom principles. Those principles include: manage portion sizes, increase convenience, improve visibility, 
enhance taste expectations, utilize suggestive selling, and set smart pricing strategies. These principles will then transcend into the following improvements: 1) increased fresh fruit and vegetable consumption, 2) increased consumption of low-fat white milk, and 3) decreased consumption of high-fat and high-calorie foods.

\section{Nudge Student Assessment Tool}

To our knowledge, there is not a tool that measures and scores whether a high school cafeteria is a "smarter lunchroom", nudging students towards healthier choices. A user-friendly audit assessment tool would be beneficial for school cafeterias to self-assess their own lunchroom environment. This resource could then be available for adoption for community stakeholders involved in the National School Lunch Program (NSLP). It would provide evaluation and suggestions on current cafeteria environments and identify areas of strength and areas of opportunities for improvements to nudge behavior change in those that eat in these environments. Once the areas within the cafeteria that need improvement are identified, no- to low-cost recommendations will be given.

\section{Study Objectives}

The purpose of this observational research project was to investigate which aspects of the current cafeteria environment in three West Virginia (WV) high schools may be influencing students to make less than optimal food choices. The primary objective was to conduct an observational-baseline assessment to determine the aspects of the cafeteria environment that promote unhealthy and healthy food choices amongst high school students. The secondary objective was to gather information that will enable the development of low- or no-cost 
interventions based on behavioral economic principles that could potentially be implemented in each of the three high schools. 


\section{CHAPTER II}

\section{REVIEW OF LITERATURE}

\section{Behavioral Economics}

The theory of behavioral economics breaks down the psychological decision-making process. It combines models from psychology and economics. ${ }^{1}$ This approach has been linked to the prevention of obesity in recent years. ${ }^{2}$ Behavioral economics theory has led to understanding why people make the choices they do when consuming and selecting certain foods. Factors that specifically relate to behavioral economics and food choice include "product placement, package size, and fixed-cost pricing (e.g., "all you can eat" buffets)." ${ }^{3}$ All of these aspects could possibly nudge people toward choosing the healthy option rather than the unhealthy option.

The United States Department of Agriculture (USDA) funded a study conducted in 2007 that integrated the structures of psychology, behavioral economics and food marketing. ${ }^{3}$ The purpose was to prove that socioeconomic status, food price, and nutritional information are not the only determinants for people's food choices. ${ }^{3}$ Other factors include nutrient content, accessibility, availability and emotional thought. Evidence-based research shows that the availability of foods can create a rise in consumption, which encompasses the economic side of the theory. ${ }^{3}$ The psychology portion is slightly more complicated. The article "Choices" simplifies it down to two different ideologies. Reactance and self-attribution are the terms that are used. Reactance is defined as one feeling pressured to make a certain decision and then doing the complete opposite. ${ }^{5}$ Self-attribution is when a person has the choice to make his or 
her own decision and feels satisfied about the choice. Each of these principals is used throughout many behavioral economics interventions involving food choice.

Therefore, in a school cafeteria, the goal for behavioral economic interventions is to nudge the students toward the healthier options without making them aware that this nudge is taking place. ${ }^{4}$ There are some disadvantages to this type of approach; such as the factor of personal choice. Research has shown that people may not be nudged to a healthier option because of their existing preferences for certain foods. Just et al. refer to one example where existing preferences win out and students stick with the unhealthy option. They conducted a study through a 4-H program that first offered unhealthy items as the default option with the healthy items offered as the alternative. The children were served French fries as the side and asked if they wanted to exchange the French fries for "apple fries" which were pealed and sliced apples. Only one student wanted the "apple fries." A couple of days later, the researchers did the complete opposite. They offered the apple slices as the default option but then asked if the students wanted fries as the alternative. Every student except one took the French fries. ${ }^{4}$ So even though it was believed that offering the healthy option as the default would lead to more students choosing apple slices, their existing preferences prevailed showing that nudges don't always work.

\section{Application of Behavioral Economics in Cafeteria Environments}

So how can behavioral economics principles be implemented in a school cafeteria environment and create a positive change in student food choice $?^{5}$ One study examined how to increase the consumption of healthy foods by simply altering the convenience of the serving lines. The intervention was conducted during a 16-week period, which was divided into two 8- 
week periods. The first being the control period and the second being the intervention period. ${ }^{5}$ The intervention was implementing a healthy convenience line. This made the healthy food items more accessible to the students because this food line was faster and more convenient for students. Researchers collected data on food items that were purchased and consumed before and after intervention. The convenience line produced an increase in the healthier items sold by $18.8 \%$; however, that does not mean that the students actually consumed those items, many of the healthy food items that students took were thrown away and not eaten. ${ }^{5}$ However, there was a decrease of $27.9 \%$ in the amount of less-healthy foods consumed. ${ }^{5}$ Overall, the intervention did nudge the students to choose the healthy options; but, the students did not consume more healthy options. The students still consumed the foods that they preferred rather than the healthy items. Even though the healthier options were not consumed, there was still a decrease in the amount of unhealthy items being consumed. ${ }^{5}$ Therefore, there are benefits to this type of behavioral economics intervention. There is a connection missing between choosing the healthy option and then actually consuming it. This could be improved through enhancing the quality of food being served, along with nutrition education for the students in school. ${ }^{5}$

\section{Competitive Foods}

The unhealthy foods items that are sold outside of the school lunch program are referred to as "competitive foods." Unlike the reimbursable meals provided to students through the National School Lunch Program (NSLP), competitive foods do not need to follow the "federal nutrition guidelines." ${ }^{6}$ Items sold as an a la carte option and in vending machines are considered to be competitive foods. ${ }^{6}$ The study "Trying Alternative Cafeteria Options in 
Schools" (TACOS) was conducted in 2000, looking at the influence competitive foods have on students' food choices, primarily wanting to increase the availability of low-fat options within the competitive foods sector.

The study conducted an inventory on 20 schools in Minnesota regarding their a la carte and vending machine options. Each school in the study had ice cream and nachos and cheese available to the students daily, and only $35.4 \%$ of the foods were low-fat options. Vending machines were in 12 of the schools and $88 \%$ provided snacks and $37 \%$ provided soft drinks throughout the entire school day. ${ }^{6}$ Findings were concerning to the researchers. It could cause a false implication that these types of high-fat foods are acceptable at all times of the day. This could create unhealthy behaviors at an early age.

Another study conducted in South Carolina analyzed 20 middle schools and their a la carte sales. The researchers understood the importance quality nutrition has at the middle school age. The consumption of sugared-sweetened beverages is at an alarming rate and makes up a larger portion of the a la carte items sold. ${ }^{7}$ Out of the 122 beverages that were not milk, 43 were carbonated beverages and 110 competitive unhealthy snacks were sold throughout all locations. Those snacks included candy, cakes and salty snacks.

One study assessed 395 public schools within the United States on their policies and food environments. Using the School Nutrition and Dietary Assessment (SNDA-III), data were collected on the United States Department of Agriculture (USDA) school lunches. ${ }^{8}$ The SNDA-III is an assessment conducted by the Food and Nutrition Service (FNS) that provides information to the public on current school meals, nutrition content, environment, and factors that influence food choice. ${ }^{9}$ The assessment looked at a la carte, vending machines, and 
competitive foods options. It was broken down into three different sections based on grade. There also was an environment score given to the schools from 0-7 with 0 being the least healthy and 7 being the healthiest. The result showed that the lower grade levels were considered to be "healthy" and the higher grade levels were considered to be "unhealthy". ${ }^{8}$ Students in higher grade levels have more freedom to choose what they want. ${ }^{8}$

These competitive items can take precedence over nutritionally healthy eating in the schools. Students can be very impressionable when it comes to what they eat at school. Friends, personal preferences and the environment all contribute to a student's food choice. Therefore, one way to reduce unhealthy eating habits would be for school lunch policies to restrict the availability of these items to the students.

A study conducted in Texas looked at certain food sales post-implementation of nutrition policies. In 2004, school nutrition guidelines were implemented to restrict the portion sizes of those snacks that are high in fat and sugar, limiting sugar-sweetened beverages to less than 12 ounces, limiting the number of times high-fat vegetables (such as French fries) are served, and milk must contain $1 \%$ or less fat. ${ }^{10}$ The study was conducted statewide and assessed the effectiveness of the new policies. Each school provided a summary of all of the items sold throughout the entire study, which was conducted over a two-year period. The amount of high-fat vegetables that were offered significantly decreased as a result of the policy that limited their offerings. Also, the amount of high-fat and high-sugar items that were sold significantly decreased. Therefore, by simply changing the policy, the items that were offered and served did show improvement just within the first two years of being implemented. ${ }^{10}$

\section{National School Lunch Program Policy}


The National School Lunch (NSL) Program has made tremendous strides over the past few years. West Virginia's written policy is one of the strictest programs in the country. ${ }^{11}$ It is important to note that this is a policy with no measured outcome published to date within the state. Vending machines are not allowed to be in service during schools hours, there are no a la carte items sold in competition with the national school lunch program; and, only $100 \%$ fruit juices are available during lunch, which are just a few of the NSL program rules and regulations. ${ }^{12}$ There are strict nutrient guidelines for the foods that are available to the students. Some of the guidelines include providing at least six grams of naturally occurring dietary fiber from the meal, limit the sodium to no more than 1100 milligrams, and provide at least one third of the student's Recommended Dietary Allowances for calories, protein, calcium, iron, and vitamins $\mathrm{A}$ and $\mathrm{C}^{12}$ These changes have not gone unnoticed. Every six years the Centers for Disease Control and Prevention (CDC) puts out the School Health Policies and Practices Survey. This is a national survey that "assesses school health policies and practices at the state, district, school, and classroom levels." ${ }^{13}$ A few questions from the survey include "'How have key policies and practices changed over time?,' 'What are the characteristics of each component of school health at the state, district, school, and classroom levels and across elementary, middle, and high schools?,' and 'Are there persons responsible for coordinating and delivering each school health program component, and what are their qualifications and educational backgrounds?'”13

After the surveys are returned, each state receives a report card. According to West Virginia's report card, the state received high marks for restricting junk foods or a la carte items in competition with the National School Lunch Program. But received low marks for design and 
layout of facility. West Virginia has made some great improvements by making policies restricting competitive foods, placing stricter regulations on vending machines, and setting stronger nutrition guidelines. However, West Virginia is still one of the leading states for adolescent obesity.

\section{Choice Architecture}

New approaches are needed to reduce the obesity epidemic. ${ }^{14}$ The book Nudge by Richard Thaler and Cass Sunstein goes into great detail about some of these new approaches. One definition that is referred to in the book is called "choice architecture."15 Choice architecture is how possible selections are presented. Studies have shown that altering the way food is presented can increase (or decrease) the consumption of the food.

One study applied this theory by using a labeling system and making healthy food options more convenient and visible in a hospital cafeteria. ${ }^{14}$ The study was over a six-month period. Food items were labeled by color. The labeling system color-coded foods using red, yellow or green based on their nutrition labels. This color scheme is from the United States Department of Agriculture My Pyramid Guidelines. ${ }^{14}$ Green represented healthier options, yellow represented mid-range healthful choice, and red represented unhealthy options. When participants entered the cafeteria, they were aware of the changes and signage was posted to explain the new labeling system. The signage explained that the red items should not be consumed very often, the yellow was "less often," and the green items were meant to be consumed as often as possible. ${ }^{14}$

The second intervention in the study targeted the convenience and availability of beverages, sandwiches and chips. The beverages were rearranged so that the green items were 
at eye level, with the red and yellow items below; the sandwiches and chips were organized in the same way. This type of intervention has been shown to be very effective. Out of the 977,793 items sold in the cafeteria, $42.2 \%$ of those items were green items and $24.9 \%$ were red items. Also, out of the 199,513 beverages sold $51.7 \%$ were green labelled. ${ }^{14}$

In 2009, a movement was created that dedicates its studies to choice architecture and guiding students toward healthier choices. This movement is known as the Smarter Lunchrooms Movement. Established by Dr. Brian Wansink and Dr. David Just, the duo conducts their research at the Cornell University Food \& Brand Lab. They also created the Cornell Center for Behavioral Economics in Child Nutrition Programs (the B.E.N. Center) where they have published many research articles since 2010.

\section{Smarter Lunchrooms Movement}

The Smarter Lunchrooms Movement is based on a set of principles that nudges students toward healthy eating. Those principles focus on convenience, portion sizes, availability, pricing strategies, taste expectations, and selling techniques. ${ }^{16}$ These six principles are used to encourage healthy eating behaviors in students. It is suggested that people usually consume more when the portions are larger, and they consume less when the portions are smaller. If the availability, convenience and visibility of the food are improved then consumption of that product would more than likely increase. These tactics can be used effectively with healthy items in the lunchroom setting. Taste expectations can be enhanced by simply making the food look more appealing or by changing the name of the food to sound more appetizing. Verbal prompts and advertisements can be used to promote healthy eating. A verbal prompt is a statement about the product that could affect a person's choice. Selling techniques also can 
affect food selection, by grouping certain items together or offering a reduced price on the healthier options. ${ }^{16}$

\section{Visibility and Availability of Fresh Fruits and Vegetables}

Several studies have conducted many interventions around these principles. For example, one study focused on increasing vegetable consumption in 8- to 11-year old children. The intervention focused on changing the name of carrots to see if that would change the children's perception of the vegetable, resulting in an increased consumption of the vegetable. The study was composed of two parts; the first part involved changing the name of the carrots to (1) "X-ray Vision Carrots," (2) "The Food of the Day," and the third option was not named. ${ }^{17}$ The results showed that the children were more likely to eat their carrots when they were named "X-ray Vision Carrots" than when the other two names were used. The second part of the study looked at two different elementary schools within the area, which had almost identical results. By altering the names of all the vegetables served that day, consumption was increased across all vegetables. For example, the broccoli selection increased by $109.4 \%$ when the name was changed to "Power Punch Broccoli."17 This study is a great example of enhancing taste expectations with no cost.

Research shows that enhancing the visibility of food will result in an increased desire for that food. ${ }^{18}$ A Cornell study wanted to prove this theory by using behavioral economic principles. The study was conducted in a middle school in New York. The middle school had the option for students to build their own salad at a salad bar that was initially placed against a wall in the lunchroom. However, this arrangement made the salad bar inconvenient for the students to get to and created a long wait in line when a student would purchase their lunch. Therefore, 
the intervention moved the salad bar 90 degrees to increase availability for the students to get a salad. This way, there were two sides available for students and they had to walk around it to get to the registers. The results showed that this increased salad bar sales by $21 \%{ }^{4}$ This study showed that by increasing the availability of food, sales can be increased.

Another study conducted at the BEN Center observed the consumption of vegetables by junior high school students. Researchers focused on allowing the students to have options they could choose from for lunch. One half of the students were given the option between carrots and celery while the other half of the students were told they had to take carrots. Of the students who were given the option, $91 \%$ consumed the vegetable while the students who were not given a choice; only $69 \%$ consumed the vegetable. ${ }^{4}$ This shows that increasing options also can increase consumption. ${ }^{4}$

Another study performed through Cornell conducted an entire makeover on a lunchroom. It did not specify the types of interventions that were implemented; only that it was called a "smarter lunchroom makeover."19 Interventions were conducted over a one-month period. Tray waste was evaluated on the vegetable, fruit, and starchy sides. ${ }^{19}$ The results indicated that consumption of fruit increased by $18 \%$ and vegetable consumption was increased by $25 \%{ }^{19}$ It was noted that all of these interventions were very low cost and with significant outcomes. $^{19}$

\section{Portion Control}

Portion size is another factor that has been addressed throughout the Cornell based research. One study tested different hypotheses regarding bowl size and how that affects food consumption, specifically looking at ice cream consumption. The study included graduate 
students and staff in nutrition from Midwestern University. ${ }^{20}$ Participants received a bowl and a spoon for a self-serve ice cream line. The bowl was either $17 \mathrm{oz}$. or $34 \mathrm{oz}$. and the spoons were either $2 \mathrm{oz}$. or $3 \mathrm{oz}$. Participants were also asked to complete a survey regarding their perception on the amount of ice cream that was in their bowl. The results showed that the people with the larger bowls ending up putting 31\% more ice cream in their bowls compared to those with the smaller bowls. Also, those who were given 3 oz. spoons served and consumed $14.5 \%$ more ice cream than the participants with 2 oz. spoons. ${ }^{20}$

\section{Implications for School Health}

There are possible areas of research to better understand choice architectures role and potential for behavior change in WV high schools. For example, to our knowledge, there is not a tool that is used for determining if a lunchroom is a "smarter lunchroom." As previously stated, there are guidelines and checklists that Cornell has created; however, it is not an assessment tool for school cafeterias. If better food choices are made over time, obesity rates and the development of subsequent chronic disease could potentially be decreased. There is also potential for an increase in the consumption of fruits and vegetables, a decrease in high calorie snack consumption, and an increase in the consumption of low-fat milk. If schools were able to assess their current lunchroom environment, they would be able to determine strengths and areas of improvement within the cafeteria. In identifying areas of improvement schools would be able to make low- to no-cost interventions, thus creating a healthier environment for students. 


\section{CHAPTER III}

\section{METHODOLOGY}

\section{Community Based Stakeholder Partnership}

A community based participatory research approach was used for the study. This approach uses stakeholders within the community for the development of the study. The stakeholders played a key role right in the beginning stages of the study. Permission needed to be obtained from the local Board of Education to be able to conduct the assessments. The study initially had a total of five schools that were to be recruited for the study. However, in one of the schools, students were allowed to leave campus during lunchtime. This is the only school in the state that has this policy and not the common theme for the state. Thus, this site was no longer considered. Permission could not be obtained to conduct the assessments in several other schools that were approached. The final sample consisted of three high schools in the state of WV. The three high schools were all located in the same county in WV. Permission was obtained from the county board of education (BOE). In January of 2013, a meeting with the Superintendent and the Board of Education was held to explain the project and timeline. Once this was completed, relationships were created with the Foodservice Director of the County as well as all of the schools principals and cafeteria staff. The project was then presented at a Board of Education meeting to inform board members about the project and what would be going on in the high schools. The next step was to set up a pre-observational day with each site. The pre-observational day included meeting the principals and cafeteria staff, taking pictures of the cafeteria, drawing the outline of the cafeteria, and assessing the area for video placement. This was all provided through cafeteria staff recommendations and feedback. During the pre- 
observational days, the research team gathered information on the current cafeteria situation from the stakeholders. This helped with the development of the written assessment tool, video assessment tool, and post-site-visit questions. The partnership with the stakeholders was crucial for this project and very beneficial. Figure 1 shows the stakeholders within the CBPR approach.

Figure 1: Community-Based Participatory Research Approach

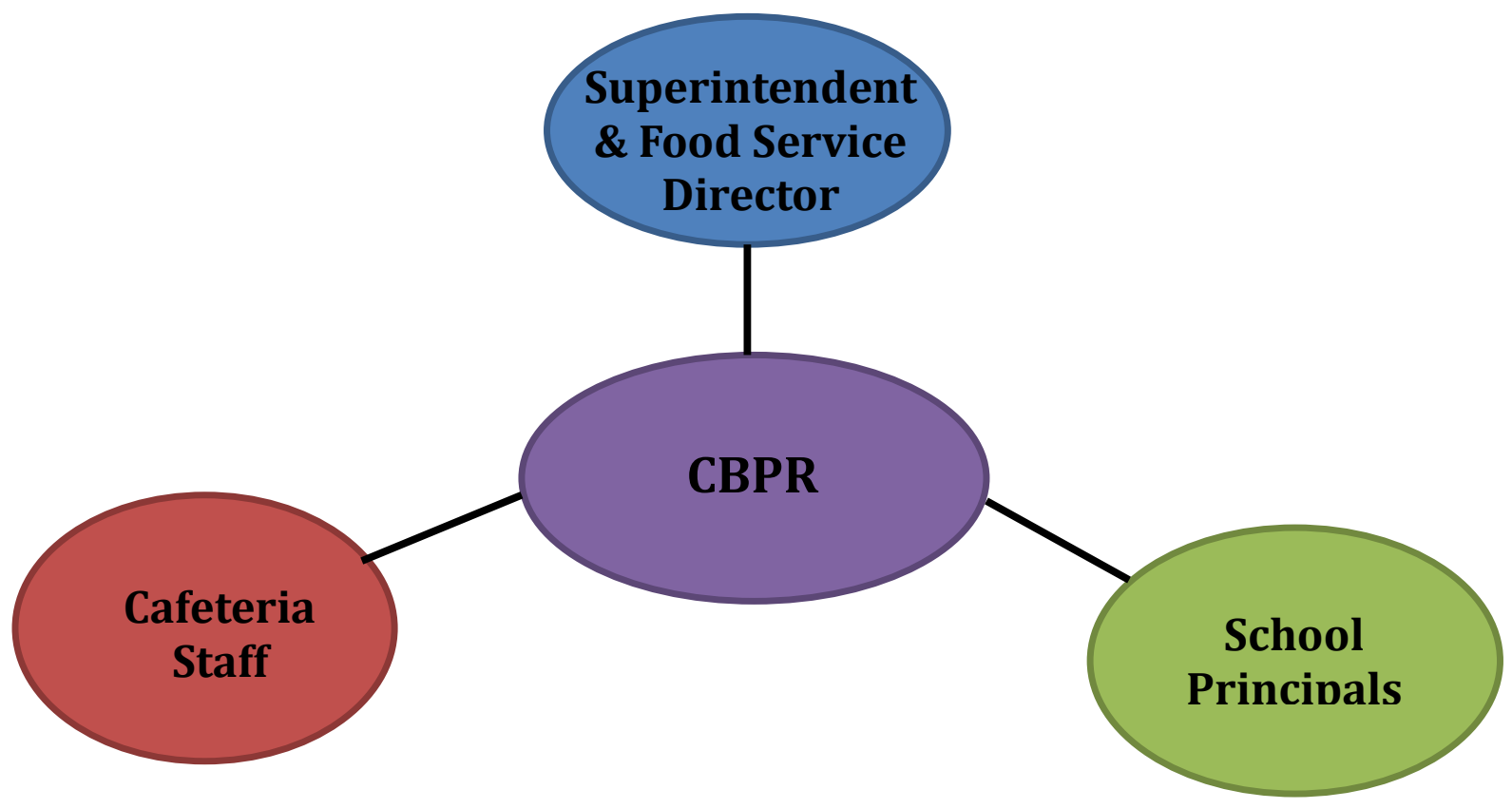

\section{IRB and Training of Research Team}

The Institutional Review Board (IRB) at West Virginia University was contacted about the project. The project was explained in great detail and the IRB contact stated that since the goal of the project was to assess the cafeteria and food service set up and not to involve students in any way, IRB approval was not needed. After considerable development and expert review of the assessment tool and the process of video data collection was determined, 
the research team completed the Café Nudge training. There were a total of five researchers that completed the Café Nudge training. The training consisted of an overview of the project, an explanation of the assessment tool, and video camera handling, one month prior to the observation days. The researcher that developed the tool went over each of the eight components that made up the tool in great detail with the team. There were three types of questions that were used throughout the tool and instructions were given on how to answer each question. For example, answers to Likert scale (1-5) questions were based on the researcher's opinion. Yes-no questions and multiple-choice questions were also used for the tool. Each team member was given one or more components of the tool and only completed their specific component(s) at each site. Table 1 shows the components each researcher was assigned.

Table 1: Assigned Tool Components to Researchers

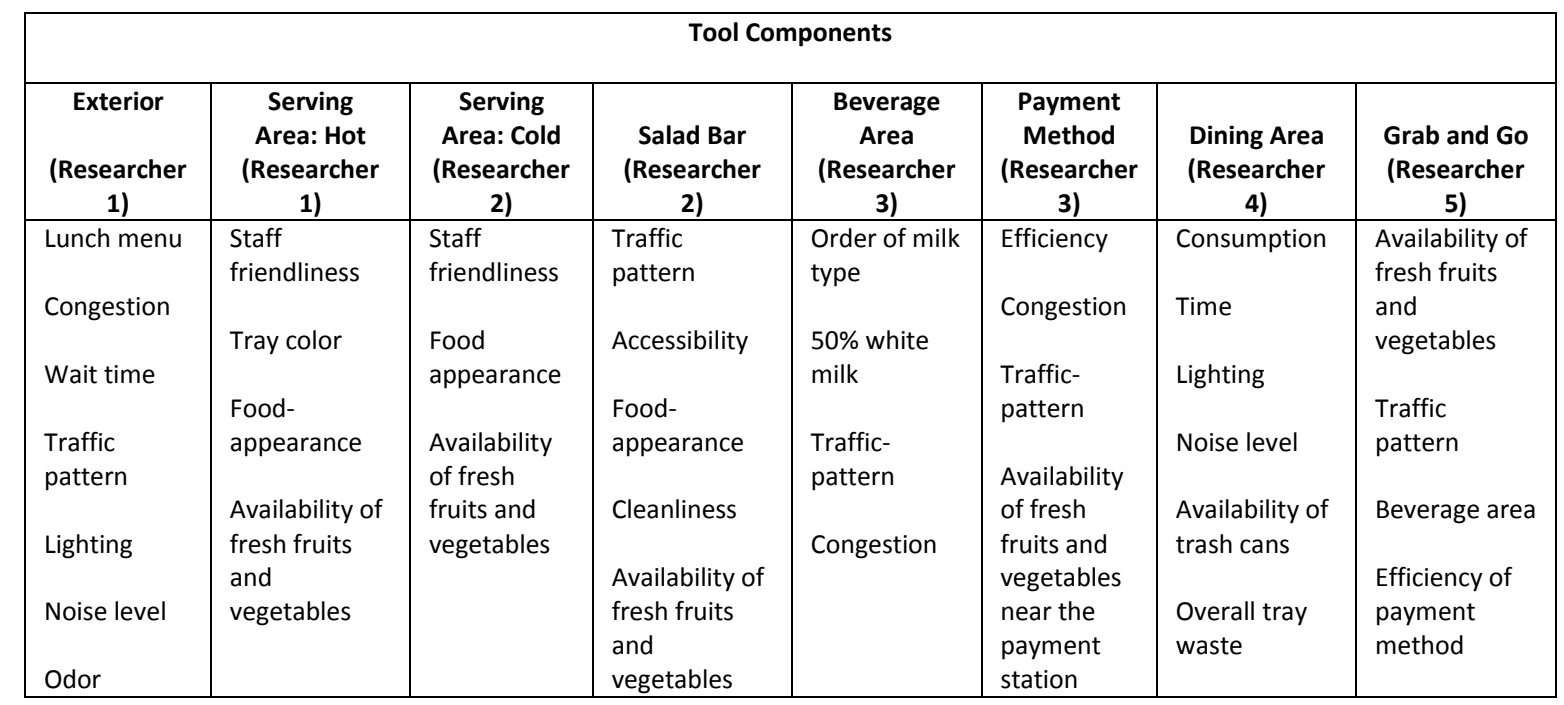

\section{Timeline of Café Nudge Project}

The development of the observational study, titled Café Nudge Project took place 
from 2013 to May of 2014. In January of 2013, permission was obtained to go into three high schools in West Virginia. Once permission was obtained the assessment tool had to be developed to assess the current cafeteria situation. After development of the Nudge Student Assessment Tool (NudgeSAT) the research team had to be trained on how to complete the tool, how to handle a video camera, and a brief overview of the project. Tool development and team training took place during February of 2013.

One day was spent in March 2013 for a baseline pre-observation-day assessment in each of the three high schools. This was conducted to view the layout of the cafeteria and receive input from the stakeholders. Refer to appendices $D, E$, and $F$ to view the cafeteria floor plans. During the month of April the research team conducted the observational day and went into each site for the entire lunch period. At sites \#1 and \#2, the lunch period consisted of three different times students had lunch. Where the students were located in the school determined what time they had lunch. Site \#3 was small enough to only have one time for lunch. The written assessment tool was completed and video footage was taken on the observational day. The team went in to each high school one hour prior to the lunch period to take pictures and complete the written assessment tool. During the lunch period, the researchers videotaped the students moving through the lunch line and completed post-site-visit questions once all the lunch periods were over. The post-site-visit questions asked about the strengths, weaknesses, and any unique aspects of each of the cafeteria environments.

From May through December of 2013 the data was analyzed. Each site was given a NudgeSAT score and videos were analyzed for certain themes. Recommendation reports were then written from January to March of 2014. The reports included NudgeSAT scores, video 
analyses, and strengths and weaknesses for each site. The final results were then presented to the Board of Education for the county in March 2014.

\section{Figure 2 -Café Nudge Timeline}

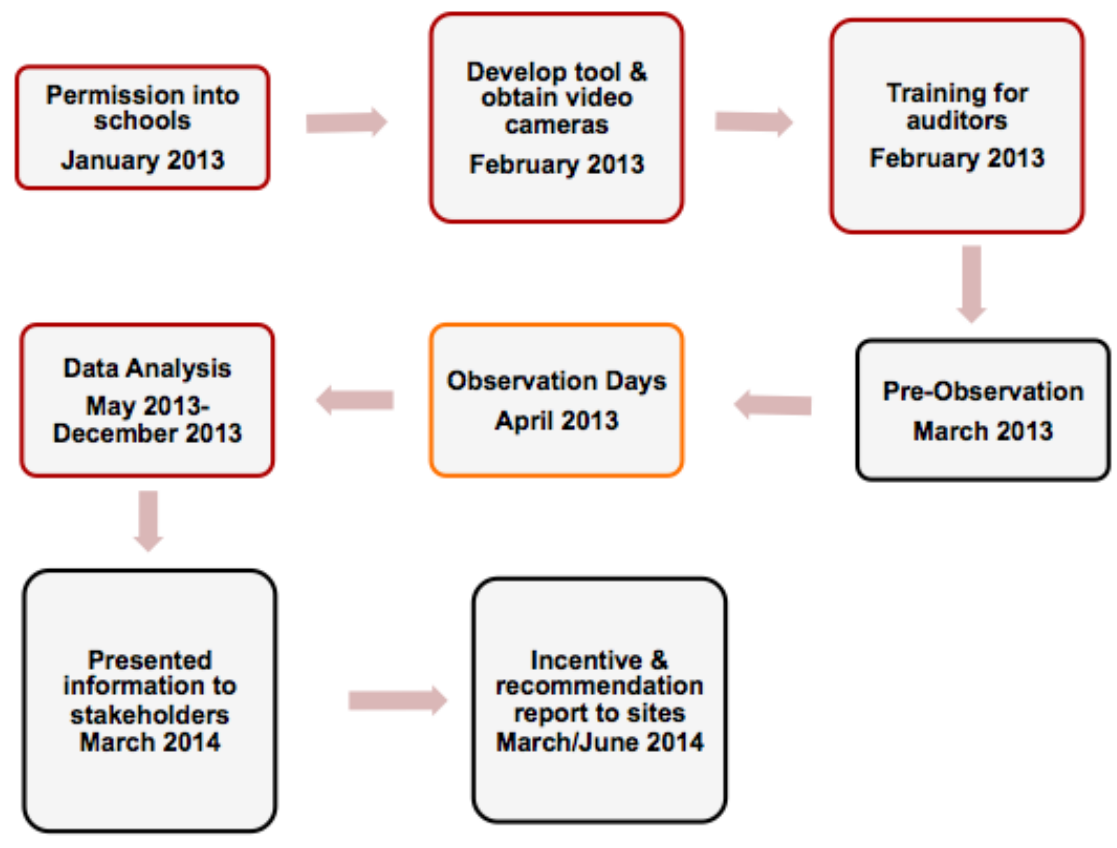

\section{Part 1 - NudgeSAT Development and Application}

This was a two-part observational study. The first part was the development and application of an assessment tool for high school cafeterias. The second part of the study was an observation done via video as well as the post-site-visit questionnaire. The assessment tool that was created is called NudgeSAT (Nudge $\underline{\text { Student }}$ Assessment $\underline{T}$ Tool). This was composed of the 6 different categories that, according to the BEN Center, make up a smarter lunchroom. Those categories include: managing portion sizes, increasing convenience to healthy foods, improving visibility of healthy foods, enhancing taste expectations, utilizing suggestive selling, and setting smart pricing strategies. The tool has eight different components: exterior, hot serving area, cold serving area, salad bar, beverage area, payment station, dining area and grab- 
n-go (only site \#1 and site \#2 had this option). Each component was identified with a score

(higher score equals more healthier components offered). The questions were created from a document produced from the BEN Center that looks at different characteristics that nudge students toward healthier choices.

Figure 3: BEN Center Characteristics for a Smarter Lunchroom

\begin{tabular}{|c|c|c|c|c|c|c|c|}
\hline \multicolumn{8}{|c|}{ NudgeSAT Components } \\
\hline Exterior & $\begin{array}{c}\text { Serving } \\
\text { Area: Hot }\end{array}$ & $\begin{array}{l}\text { Serving } \\
\text { Area: Cold }\end{array}$ & Salad Bar & $\begin{array}{c}\text { Beverage } \\
\text { Area }\end{array}$ & $\begin{array}{l}\text { Payment } \\
\text { Method }\end{array}$ & Dining Area & Grab and Go \\
\hline $\begin{array}{l}\text { Lunch } \\
\text { menu }\end{array}$ & $\begin{array}{l}\text { Staff } \\
\text { friendliness }\end{array}$ & $\begin{array}{l}\text { Staff } \\
\text { friendliness }\end{array}$ & $\begin{array}{l}\text { Traffic } \\
\text { pattern }\end{array}$ & $\begin{array}{l}\text { Order of } \\
\text { milk type }\end{array}$ & $\begin{array}{l}\text { Efficiency } \\
\text { Congestion }\end{array}$ & $\begin{array}{l}\text { Consumption } \\
\text { Time }\end{array}$ & $\begin{array}{l}\text { Availability of } \\
\text { fresh fruits and } \\
\text { vegetables }\end{array}$ \\
\hline $\begin{array}{l}\text { Congestion } \\
\text { Wait time }\end{array}$ & $\begin{array}{l}\text { Tray color } \\
\text { Food- }\end{array}$ & $\begin{array}{l}\text { Food } \\
\text { appearance }\end{array}$ & $\begin{array}{l}\text { Accessibility } \\
\text { Food- }\end{array}$ & $\begin{array}{l}50 \% \text { white } \\
\text { milk }\end{array}$ & $\begin{array}{l}\text { Traffic- } \\
\text { pattern }\end{array}$ & Lighting & Traffic pattern \\
\hline Traffic & appearance & $\begin{array}{l}\text { Availability } \\
\text { of fresh }\end{array}$ & appearance & $\begin{array}{l}\text { Traffic- } \\
\text { pattern }\end{array}$ & Availability & Noise level & Beverage area \\
\hline $\begin{array}{l}\text { pattern } \\
\text { Lighting }\end{array}$ & $\begin{array}{l}\text { Availability of } \\
\text { fresh fruits } \\
\text { and }\end{array}$ & $\begin{array}{l}\text { fruits and } \\
\text { vegetables }\end{array}$ & $\begin{array}{l}\text { Cleanliness } \\
\text { Availability }\end{array}$ & Congestion & $\begin{array}{l}\text { of fresh } \\
\text { fruits and } \\
\text { vegetables }\end{array}$ & $\begin{array}{l}\text { Availability of } \\
\text { trash cans }\end{array}$ & $\begin{array}{l}\text { Efficiency of } \\
\text { payment } \\
\text { method }\end{array}$ \\
\hline Noise level & vegetables & & $\begin{array}{l}\text { of fresh } \\
\text { fruits and } \\
\text { vegetables }\end{array}$ & & $\begin{array}{l}\text { near the } \\
\text { payment } \\
\text { station }\end{array}$ & $\begin{array}{l}\text { Overall tray } \\
\text { waste }\end{array}$ & \\
\hline
\end{tabular}

Once questions were identified, the written tool was created using Qualtrics which is an online survey creator. Community stakeholders who were identified as experts reviewed the tool and then corrections were made based on their review. The final assessment tool was the Nudge Student Assessment Tool (NudgeSAT).

NudgeSAT contained three different types of questions. Yes or no questions, multiplechoice questions, and Likert scale questions. Each team member received a paper copy of the tool for each site. When all the assessments were completed the answers were plugged back into Qualtrics, which created an Excel spreadsheet of the results. For the yes-no questions, a yes answer received one point and a no answer received zero points. If a no answer was 
considered a positive aspect then it received one point. The multiple choice questions also received one point for a specific answer. The Likert scale questions were used for the following aspects: congestion, food preparation smell, noise level, lighting level, and food appearance.

The exterior component contained questions that examined the exterior portion of the cafeteria which included: congestion within the area, wait time within the line, if the lunch menu was posted, traffic pattern, lighting, noise level, and odor. The questions regarding congestion, lighting, noise level, and odor were based on a 1-5 Likert scale. Each site could receive a total of 16 points for the exterior portion of the tool. The hot and cold serving areas were made up of questions based on staff friendliness, tray color, food-appearance and availability of fresh fruits and vegetables. Food appearance was based on a 1-5 Likert scale. Each site could receive a total of 22 points in the hot serving area and a total of 21 points from the cold serving area component. The salad bar questions add up to a total of 10 points. The questions focused on the accessibility and convenience of the salad bar, food appearance, cleanliness, and the availability of fresh fruit and vegetables.

The beverage area was scored on the order of milk type within the beverage container, if the beverage area contained at least $50 \%$ white milk, traffic-pattern to the beverage container, and the amount of congestion within the area. Each site could receive up to 7 points for the beverage area. The payment station component looked at the efficiency of the payment method, the congestion within the area, traffic-pattern, and the availability of fresh fruits and vegetables near the payment station. There was a total of 5 points that could have been awarded. The dining area was the next component. These questions measured the amount of time the students had to consume their lunch, overall tray waste percentage, lighting, odor, 
and noise level within the area. There was a total of 20 points that could have been awarded for this component. The last component was the grab and go station. A grab and go station provides students a quicker way to receive their lunch. Grab and go stations usually consist of a prepackaged lunch for the students. Students are able to grab their lunch and take it to a desired location. These questions focused on availability of fresh fruits and vegetables, traffic pattern, beverage area, and efficiency of payment method. A total of 27 points could have been awarded for the grab and go component. The highest overall score a site could receive was 128. However, the total score for site \#3 was out of 102 , since it did not have a grab and go option.

\section{Part 2 - Video Observation \& Post Site Questions}

The videos were recorded in these four areas of the cafeteria (if present) 1) exterior environment, 2) serving environment, 3) dining environment and 4) grab and go environment. One researcher was assigned to each of these specific environments to record. The researchers that recorded the exterior and the serving environments stood on step stools to be able to observe the flow of the students through the environments. Each researcher recorded the same environment for every lunch period at each site. Once the NudgeSAT and video recordings were completed, each team member was asked to complete three post site questions. The strengths, weaknesses, and a unique aspect at each site were to be identified. These post-site-visit questions are shown in appendix C.

\section{Data Analysis}

The NudgeSAT was analyzed based on a points system. Yes or no questions were awarded 0 or 1 point, the point being awarded for answers that indicated a positive aspect of the cafeteria's choice architecture. The multiple-choice questions received 1 point for a specific 
answer chosen. The Likert scale questions received 2, 1, or 0 points. When assessing for noise, a no noise answer received 2 points, low to medium and medium received 1 point, and loud and very loud received 0 points. When assessing for lighting, no or low lighting received 0 points, low to medium and medium received 1 point, and bright and very bright received 2 points. The congestion question received 2 points for no congestion, 1 point for slight and neutral, and 0 points for congested and very congested. The food appearance question received 0 points for poor, 1 point for low to moderate and moderate, and 2 points for appealing and very appealing. The answer to each Likert scale question was based on the researchers opinion for that site.

Each completed assessment was given an overall score and a percentage. A higher score represented a site that had more smarter lunchroom components present. The highest score a site could receive was 128 . The scores for each component at each site are presented in table 2 .

The video clips were also analyzed using a Likert scale system with answers receiving 2, 1 , or 0 points. The higher the score the smarter the lunchroom environment. The project team wanted to get outside expert opinion on whether the high school cafeterias were meeting the criteria for a smarter lunchroom, as the initial researchers had already given their opinions when filling out the NudgeSAT questionnaires. Consequently, two registered dietitians who were familiar with the Smarter Lunchrooms Movement viewed segments of the videos that were representative of each high school's lunchroom situation. Although the videos covered the full time of each lunch period (videos were up to one hour in length) it was determined that a three minute segment taken at the busiest time of each lunch period was sufficient to convey the factors that needed to be analyzed in order to give the cafeteria a smarter lunchroom 
score. Each environment was analyzed using 3 questions. Each question could receive up to two points. The points from each question were totaled and the environment was given an overall score. A total of six points could have been awarded overall. The exterior, serving, and grab and go environments were assessed for congestion, wait time, and traffic pattern. The dining environment was assessed for traffic pattern, congestion, and the amount of time students had to consume their lunch. Site \#3 was only analyzed on exterior, serving, and dining environments, since it did not have a grab and go option. The video assessment tool is shown in appendix B. These results are represented in a bar graph for each site. The post-site-visit answers were analyzed for common themes. NudgeSAT scores, video scores, and strengths and weaknesses for each site were compiled into individual site reports and these will be presented to the principals of each high school. These reports are located in appendices D, E, and F. 


\section{CHAPTER IV}

\section{RESULTS}

\section{Site Demographics}

Student numbers in each high school and school lunch sales differed among sites. Site \#3 was a combined middle school and high school, however we only assessed for the high school lunch period. The total number of lunches sold, the total number of students receiving free, reduced price, or full price lunch are shown in table 2 . The high school with 452 students is combined with the middle school. The school lunch participation could not be obtained for just the high school. The students who are not participating in the NSL program are either bringing their own lunch or not eating lunch. The sites cafeteria staff provided this information. These numbers were obtained from the Food Service Director for the observational day for each site. Site \#1 was observed on April 8, 2013, site \#2 was observed on April 15, 2013, and site \#3 was observed on April 29, 2013.

Table 2: Demographics of Sites

\begin{tabular}{|c|c|c|c|c|}
\hline $\begin{array}{c}\text { \# of } \\
\text { Students } \\
\text { in the } \\
\begin{array}{c}\text { High } \\
\text { School }\end{array}\end{array}$ & $\begin{array}{c}\text { \# of Students Who } \\
\text { Participate in } \\
\text { National School } \\
\text { Lunch Program } \\
\text { (NSLP) }\end{array}$ & $\begin{array}{c}\text { Free Lunch } \\
\text { Participation }\end{array}$ & $\begin{array}{c}\text { Reduced } \\
\text { Price Lunch } \\
\text { Participation }\end{array}$ & $\begin{array}{c}\text { Paid Full } \\
\text { Price for } \\
\text { Lunch }\end{array}$ \\
\hline 1656 & $\begin{array}{c}879 \\
(53 \%)\end{array}$ & $\begin{array}{c}240 \\
(27 \%)\end{array}$ & $\begin{array}{c}43 \\
(5 \%)\end{array}$ & $\begin{array}{c}596 \\
(68 \%)\end{array}$ \\
\hline 1251 & 746 & 184 & 53 & 509 \\
\hline 452 & $(60 \%)$ & $(25 \%)$ & $(7 \%)$ & $(68 \%)$ \\
\hline & 347 & 112 & 27 & 208 \\
\hline
\end{tabular}

Note: The percentage for the number of students who participate in the National School Lunch Program is out of the number of students in the high school. The percentages for Free Lunch Participation, Reduced Price Lunch Participation, and Paid Full Price for Lunch are out of the number of students who participate in the National School Lunch Program. 


\section{Part 1 - NudgeSAT}

Each site had areas that they excelled in as well as areas they could improve when assessing the cafeteria. Site $\# 1$ received an overall score of 73 and a percentage score of $57 \%$. Site \#2 received a 69 and 54\%, and Site \#3 received a 53 and 52\%. Site \#3 received a much lower overall score because it did not have a grab and go area, however, this was taken into consideration and its percentage score was adjusted for the missing component. Scores for each component at each site are shown in table 3 . Site \#1 received the lowest score in the grab and go component of the two schools that had a grab and go option. Of the three schools Site \#2 received the lowest scores in the exterior and payment station components. Site \#3 received the lowest scores in the hot serving area, cold serving area, and beverage area components when compared to the other two schools. When compared to the other schools Site \#1 received the highest scores in the hot serving area, salad bar, beverage area, and payment station components. Site \#2 received the highest scores among the schools in the cold serving and the grab and go components. Site \#3 received the highest score in the exterior component. All three sites had the same score for the dining area component.

Table 3: NudgeSAT Results

\begin{tabular}{|c|c|c|c|c|c|c|c|c|c|}
\hline \multirow{2}{*}{$\begin{array}{c}\text { Site } \\
\text { Location }\end{array}$} & \multicolumn{8}{|c|}{ Scores for NudgeSAT } & \multirow[b]{2}{*}{ Total } \\
\hline & $\begin{array}{l}\text { Exterior } \\
\text { (16) }\end{array}$ & $\begin{array}{c}\text { Serving } \\
\text { Area: } \\
\text { Hot } \\
(22)\end{array}$ & $\begin{array}{l}\text { Serving } \\
\text { Area: } \\
\text { Cold } \\
(21)\end{array}$ & $\begin{array}{l}\text { Salad } \\
\text { Bar } \\
(10)\end{array}$ & $\begin{array}{c}\text { Beverage } \\
\text { Area } \\
\text { (7) }\end{array}$ & $\begin{array}{l}\text { Payment } \\
\text { Station } \\
\text { (5) }\end{array}$ & $\begin{array}{l}\text { Dining } \\
\text { Area } \\
(20)\end{array}$ & $\begin{array}{c}\text { Grab } \\
\text { and } \\
\text { Go } \\
\text { (27) }\end{array}$ & \\
\hline Site \#1 & $\begin{array}{c}9 \\
(56 \%)\end{array}$ & $\begin{array}{c}10 \\
(45 \%)\end{array}$ & $\begin{array}{c}10 \\
(47 \%)\end{array}$ & $\begin{array}{c}9 \\
(90 \%)\end{array}$ & $\begin{array}{c}6 \\
(86 \%)\end{array}$ & $\begin{array}{c}4 \\
(80 \%)\end{array}$ & $\begin{array}{c}13 \\
(65 \%)\end{array}$ & $\begin{array}{c}12 \\
(44 \%)\end{array}$ & $\begin{array}{c}73 / 128 \\
(57 \%)\end{array}$ \\
\hline Site \#2 & $\begin{array}{c}8 \\
(50 \%)\end{array}$ & $\begin{array}{c}9 \\
(41 \%)\end{array}$ & $\begin{array}{c}11 \\
(52 \%)\end{array}$ & $\begin{array}{c}8 \\
(80 \%)\end{array}$ & $\begin{array}{c}4 \\
(57 \%)\end{array}$ & $\begin{array}{c}2 \\
(40 \%)\end{array}$ & $\begin{array}{c}13 \\
(65 \%)\end{array}$ & $\begin{array}{c}14 \\
(52 \%)\end{array}$ & $\begin{array}{c}69 / 128 \\
(54 \%)\end{array}$ \\
\hline Site \#3 & $\begin{array}{c}11 \\
(69 \%)\end{array}$ & $\begin{array}{c}8 \\
(36 \%)\end{array}$ & $\begin{array}{c}7 \\
(33 \%)\end{array}$ & $\begin{array}{c}8 \\
(80 \%)\end{array}$ & $\begin{array}{c}3 \\
(43 \%)\end{array}$ & $\begin{array}{c}3 \\
(60 \%)\end{array}$ & $\begin{array}{c}13 \\
(65 \%)\end{array}$ & N/A & $\begin{array}{c}53 / 102 \\
(52 \%)\end{array}$ \\
\hline
\end{tabular}

Note: Numbers in parentheses are the maximum amount of points that could be awarded for that component. Percentages in parentheses are the percentages for that specific component. 


\section{Part 2 - Video Observation}

The video observation results are shown in charts 1,2 , and 3 . Compared to the other sites, Site \#1 received the highest score in the exterior environment and the serving environment. Site \#2 received the highest score in the grab and go environment. Site \#3 received the highest score in the dining environment. Compared to the other cafeterias, Site \#1 received the lowest score in the dining environment. Site \# 2 received the lowest score in the exterior environment. Site \#3 received the lowest score for its serving environment and did not receive a score for grab and go because there was none.

Bar Graph 1: Site \#1 Video Observation Results

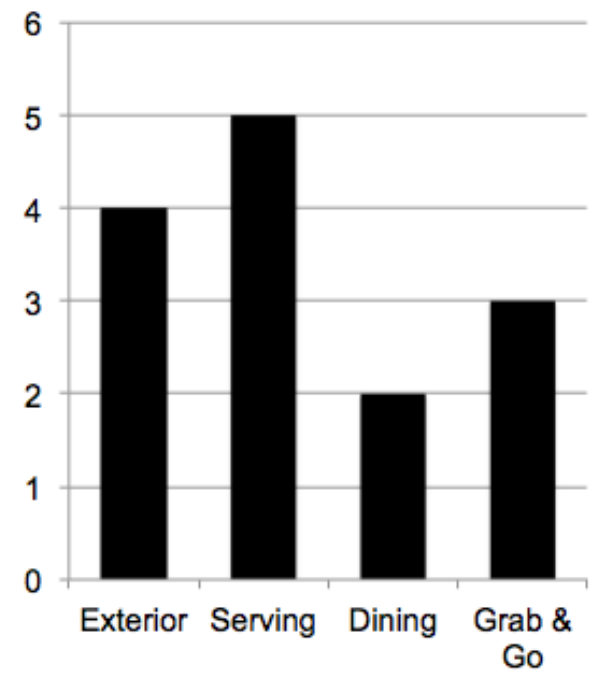

Bar Graph 2: Site \#2 Video Observation Results

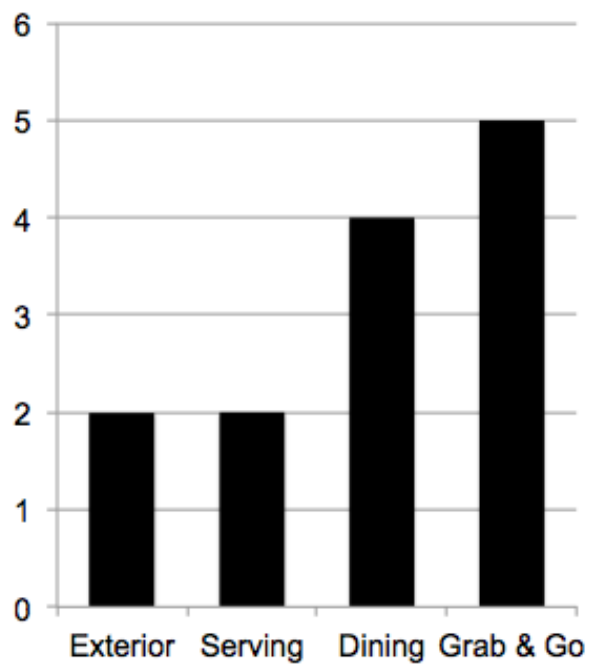




\section{Bar Graph 3: Site \#3 Video Observation Results}

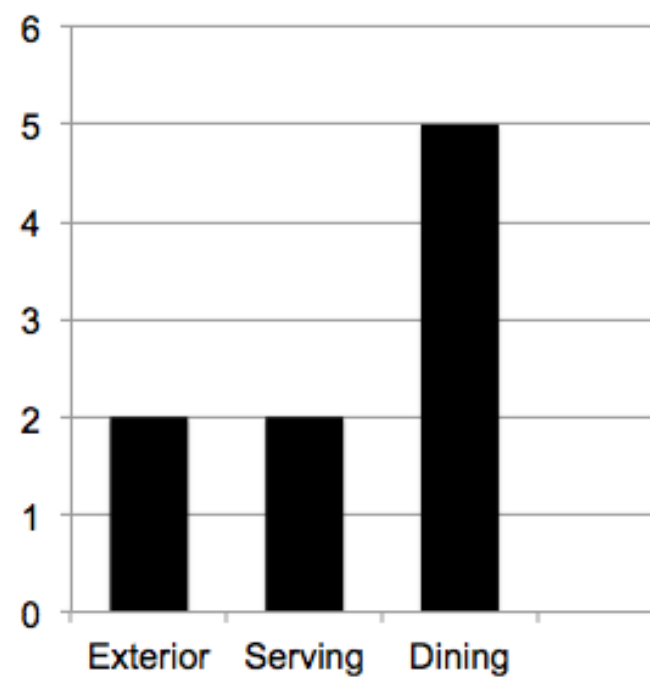

\section{Part 2 - Post-Site-Visit Questionnaire}

The post-site-visit questions are shown in appendix C. The results were grouped together by common themes found amongst the researchers answers. Site \#1's strengths were the availability of fresh fruits and vegetables at the salad bar and the efficiency of the payment station. Site \#2's strengths were the lighting and the amount of space within the cafeteria as well as all of the pre-packaged and precut fresh fruits and vegetables available at the end of the serving line. Site \#3's strengths were the cleanliness and the very friendly staff within the cafeteria. Site \#1's weaknesses were the inaccessibility of the salad bar and the staff lacked interaction with the students. Site \#2's weakness was also the inaccessibility of the salad bar. There was a clear plastic shield on the salad bar that made it difficult for the students to reach the items. Site \#3's weaknesses were the congestion and limited amount of space within the serving environment of the cafeteria.

\section{Recommendation Reports}


Each site will receive a recommendation report and monetary donation for participating in this observational study. The recommendation reports include their NudgeSAT scores, video observation scores and strengths and weaknesses identified by the researchers. The monetary donation will be used for implementing smarter lunchroom components that would improve the cafeteria environment and encourage healthier food choices by the high school students. Refer to appendices D, E, and F for a full recommendation report for each site. 


\section{CHAPTER V}

\section{DISCUSSION}

\section{Application of NudgeSAT}

During the development of Café Nudge there was no assessment tool and scoring system to assess whether cafeterias in high schools are considered a "smarter lunchroom" or not. However, in 2013, after this study was conducted, the BEN center put out their first Smarter Lunchrooms Assessment. The assessment is called Smarter Lunchrooms SelfAssessment. The components that make up the BEN Center's assessment are very similar to the components of the NudgeSAT, however, the scoring system is different. The BEN Center's assessment scoring is based on whether a component is present versus not present. If a smarter lunchroom aspect is present, then it receives a "check" and if not then no check is given. This is a simple scoring system and shows the areas that need improving by not receiving a check. Also, the aspects that were assessed are very descriptive and can be easily changed if not present in the current cafeteria environment. This was where the NudgeSAT fell short. In the NudgeSAT not every aspect assessed could easily be changed. For example, one of the recommendations for site \#3 was to implement a grab and go option. However, this may be difficult for the site due to space and layout design of the cafeteria. Also, the scoring system for NudgeSAT was based on expert opinion and what was found in the research. The BEN Center's check system completely eliminates scoring bias since no score or rating is given.

When looking at the six principles of a smarter lunchroom, the utilization of suggestive selling and setting smart pricing strategies were not assessed in these $3 \mathrm{WV}$ sites. In WV, high schools are not allowed to sell competitive food items so pricing strategies are not relevant and 
staff will not be able to suggest that students purchase healthy items, although they could encourage students to take the healthy offerings. But these policies differ from state to state and could substantially affect NudgeSAT scores. Therefore, the tool may need to be modified on a state-to-state level to include such parameters as money exchanged for competitive foods.

The other smarter lunchrooms principles include, manage portion sizes, increase convenience, improve visibility, and enhance taste expectations. The NudgeSAT did not contain any questions regarding portion sizes. A study conducted by Wansink et al. looked at how when people serve themselves they are likely to "over-serve and overeat". ${ }^{20}$ Therefore, implementing questions regarding if the students serve themselves could strengthen the NudgeSAT. When it comes to increasing convenience and improving visibility, the BEN Center suggests placing the healthy food items food at eye level and the unhealthy items harder to reach. ${ }^{16}$ The NudgeSAT did assess for how often the healthy items (fresh fruits and fresh vegetables) were available throughout the serving line but it did not assess if they were at eye level. Adding questions to the NudgeSAT about if healthy items were at eye level would enhance the assessment for the improving visibility principle. The enhance taste expectations principle was taken into consideration in the NudgeSAT. Food appearance was assessed on a Likert scale, however this was based on the researcher's opinion. The BEN Center suggests using attractive names for enhancing taste expectations. ${ }^{16}$ The NudgeSAT did not assess for the use of attractive names. If this was assessed, it would allow for implementation of enhancing tastes expectations within the recommendation reports. There were many strengths and areas of possible improvement within the tool itself that were learned from this pilot project and that could be incorporated in a revised NudgeSAT tool. 
The NudgeSAT was only used on three high schools in the County. This is a very small sample size and the tool may not apply to other high schools in the state as well as the country. National School Lunch Program polices vary from state to state therefore some schools may allow off campus lunch or competitive foods to be sold, and thus, the NudgeSAT tool would have to be modified.

\section{Interpretation of Data}

The composite scores from the NudgeSAT may not completely capture what was observed at each site. For example, all three sites had the same score for the dining component of the tool. However, each dining component at the sites was very different and had its own strengths and weaknesses. Even though the scores did not always capture what was actually observed there were some areas in which the tool was accurate. Site \#2 received the highest score for the cold serving area. This was very true. Site \#2 had a very large selection of pre-cut and prepackaged fruits and vegetables available to the students. These items were placed at the end of the serving line, right before the students checked out. Site \#1 received the highest score for the salad bar among the site. The salad bar had an extensive variety of fresh fruits and vegetables with bright red serving tongs to access the food items available to the students which made the food more attractive.

The results for the video observation captured the school lunchroom environment fairly well. Site \#1 received its highest score for its serving environment, which was accurate. The serving environment for Site \#1 was very spacious and students were able to move freely throughout the line and were able to go back if they forgot an item. They do not feel pressured to make a certain choice. This allows more time for the students to choose their items. Time is a 
very big issue in lunchrooms. Many students choose items based on how long it takes to receive them. ${ }^{21}$ Site $\# 2$ received the highest score for the grab and go environment. The grab and go items were packaged in clear plastic so the students were able to see exactly what they were choosing, and there was a big selection of healthy food items. Site \#3 received the highest score for the dining environment. This dining environment was spacious and allowed the most amount of time for the students to consume their lunch. In general, Americans are spending less time eating but are still consuming more calories. ${ }^{22}$ This could be explained by mindless eating. When there is less monitoring of one's eating, more calories are consumed. ${ }^{23}$ Since the students had more time to eat their lunch at Site \#3, they were less likely to mindlessly eat and be able to monitor for feeling full, thus not overeating.

\section{Study Limitations}

Each site was only observed for one day. If the sites were observed at least twice this would improve the reliability and validity of NudgeSAT. The small sample size limited testing whether the tool could be applicable to other schools in WV. The sample size originally included five sites. However, permission could not be obtained for the other two sites.

The site geographic locations need to be taken into consideration. Site \#3 was in a rural location and was a much smaller school than the other two. Sites \#1 and \#2 were located in an urban and suburban area, and each had over 1000 students. Schools throughout the state of WV are located in rural, urban, and suburban areas as well as range in size, so in that way this study is representative of the geographic and size ranges that exist in the state. This could be an important factor when assessing cafeterias for smarter lunchroom principles. Larger schools have more room within the cafeteria and usually more options for the students. The sites also 
vary in the amount of students that pay full price for lunch or receive free or reduced price lunches. Site \#3 did have the most students participating in the School Lunch Program. However, the numbers were from middle and high school combined. Each site had over $60 \%$ of students paying for their lunches, although, West Virginia recently implemented a new bill that states all students in public schools are able to receive free breakfast and lunch. After this policy has been in place for a while, additional analysis will be needed to assess the impacts on the "smartness" of the lunchroom. This program could lead to more congestion, higher noise levels, and additional problems that could decrease smarter lunchroom scores. Also, National School Lunch Program policies differ state to state. The NudgeSAT tool may not be feasible for those that allow competitive foods and/or off campus lunch. 


\section{CHAPTER VI}

\section{SUMMARY AND CONCLUSIONS}

In summary, the findings from the three sites within WV showed that the sites do not possess many smarter lunchroom components. Each site has room to improve within each component of the NudgeSAT, especially the wait time of receiving lunch, the amount of time students have to eat their lunches, and the availability and accessibility of fresh fruits and vegetables. Sites \#1 and \#2 were very similar in that they both had over 1000 students and were located in suburban areas. Site \#3 was very different from sites \#1 and\#2. Site \#3 was a combined middle and high school and was located in a rural area. The NudgeSAT could be used in high schools similar to sites \#1 and \#2. Schools that have a higher population of students and located in suburban areas and high schools with a grab and go option, would be able to use the NudgeSAT. However, the NudgeSAT was used among five different researchers. It would be beneficial to shorten the tool so fewer people can complete it and be more efficient. Grouping different components of the cafeteria environment together and eliminating repeated questions could shorten the tool. The Likert scale questions either need to be eliminated or use a standard scale to represent the different aspects. For example, noise level was assessed based on the researcher's opinion. This could vary from person to person. How the researcher assessed the noise level for one site could be different for another. There was not a set standard to determine what was considered loud or very loud.

Also, additional research is needed to assess other high school lunchrooms in WV as well as nationally to establish a better representation of the population. In future studies, 
assessing lunchrooms with the NudgeSAT will allow researchers to identify strengths and weaknesses within the area and be able to make no to low cost interventions. 


\section{REFERENCES}

1. Thaler R, Sunstein C. Nudge: Improving decisions about health, wellness, and happiness. New York Penguin Group; 2009.

2. Hursh SR. Behavioral economics. J Exp Anal Behav. 1984;42(3):435-452. doi: 10.1901/jeab.1984.42-435.

3. Gittelsohn J, Lee K. Integrating educational, environmental, and behavioral economic strategies may improve the effectiveness of obesity interventions. Applied Economic Perspectives and Policy. 2013;35(1):52-68.

4. Just D, Mancino L, Wansink B. Could behavioral economics help improve diet quality for nutrition assistance program participants? 2007. Economic Research Service: Economic Research Report. (43):1-34.

5. Just DR, Wansink B. Smarter lunchrooms: Using behavioral economics to improve meal selection. Choices. 2009;24(3):1-7.

6. Hanks AS, Just DR, Smith LE, Wansink B. Healthy convenience: Nudging students toward healthier choices in the lunchroom. Journal of Public Health. 2012;34(3):370-376.

7. French SA, Story M, Fulkerson JA, Gerlach AF. Food environment in secondary schools: A la carte, vending machines, and food policies and practices. Journal Information. 2003;93(7).

8. Pilant VB, Skinner JD. Availability of competitive foods and beverages during lunch in middle schools. TOP CLIN NUTR. 2004;19(1):20-27. 
http://search.ebscohost.com/login.aspx?direct=true \&db=c8h\&AN=2005044854\&site=ehostlive.

9. Finkelstein DM, Hill EL, Whitaker RC. School food environments and policies in US public schools. Pediatrics. 2008;122(1):251-9.

http://search.ebscohost.com/login.aspx?direct=true \&db=c8h\&AN=2009972596\&site=ehostlive.

10. Gordon A, Fox MK. School nutrition dietary assessment study-III: Summary of findings. 2007.

11. Cullen KW, Watson KB. The impact of the texas public school nutrition policy on student food selection and sales in texas. Am J Public Health. 2009;99(4):706-712. http://search.ebscohost.com/login.aspx?direct=true\&db=psyh\&AN=2009-03829013\&site=ehost-live. doi: 10.2105/AJPH.2007.129387.

12. Story M, Nanney MS, Schwartz MB. Schools and obesity prevention: Creating school environments and policies to promote healthy eating and physical activity. Milbank $Q$. 2009;87(1):71-100.

13. Stuhldreher W, Koehler A, Harrison M, Deel H. The west virginia standards for school nutrition. Journal of Child Nutrition and Management. 1998;22:79-86.

14. Centers for Disease Control and Prevention. School health program report card. http://www.cdc.gov/healthyyouth/shpps/2006/reportcards/westvirginia/RC W Virginia SHPPS2006.pdf. Updated 20062013. 
15. Thorndike AN, Sonnenberg L, Riis J, Barraclough S, Levy DE. A 2-phase labeling and choice architecture intervention to improve healthy food and beverage choices. Am J Public Health. 2012;102(3):527-533. doi: 10.2105/AJPH.2011.300391.

16. Just D, Wansink B. 6 guiding principles that improve school lunch eating behaviors. . 2011.

17. Wansink B, Just DR, Payne CR, Klinger MZ. Attractive names sustain increased vegetable intake in schools. Prev Med. 2012;55(4):330-332. doi: 10.1016/j.ypmed.2012.07.012.

18. Volkow ND, Wang G, Fowler JS, et al. "Nonhedonic" food motivation in humans involves dopamine in the dorsal striatum and methylphenidate amplifies this effect. Synapse. 2002;44(3):175-180.

19. Hanks AS, Just DR, Wansink B. Smarter lunchrooms can address new school lunchroom guidelines and childhood obesity. J Pediatr. 2013;162(4):867-869. doi:

10.1016/j.jpeds.2012.12.031.

20. Wansink B, Van Ittersum K, Painter JE. Ice cream illusions: Bowls, spoons, and self-served portion sizes. Am J Prev Med. 2006;31(3):240-243.

21. Create a healthy-items-only convenience line or window stocked with all types of healthy foods: Milk, fruits, veggies, premade sandwiches and salads, and lowest-fat/lowest-sodium entrée items. Retrieved April, 2014, from http://smarterlunchrooms.org/idea/create-healthyitems-only-convenience-line-or-window-stocked-all-types-healthy-foods-milk. 
22. Bertrand, M., \& Schanzenbach, D. W. (2009). Time use and food consumption. American Economic Review: Papers \& Proceedings, 99(2), 170-176.

23. Wansink, B. (2010). From mindless eating to mindlessly eating better. Physiology \& Behavior, 100, 454-463. 


\section{APPENDICES}

\section{Appendix A: Nudge Student Assessment Tool}

What high school did you observe?

Are there "healthy" posters or signage within the area? (healthy defined as nutritional or promoting a healthy lifestyle)

Y Yes (1)

No (0)

Is there a lunch menu posted within the area?

Y Yes (1)

No (0)

Is the lunch menu neat and clear to read?

Y Yes (1)

O No (0)

Is the area where the utensils are located, clean and free from clutter?

O Yes (1)

O No (0)

Are the trays brightly colored?

Yes (1)

O No (0)

What is the color of the tray?

O White (0)

Black (0)

O Yellow (0)

Red (1)

O Other (0)

Are there food placement directions for the tray to inform students where to place each type of food and milk?

Yes (1)

No (0) 
Are there any "verbal prompts" being provided to the students while they stand in line? (A verbal prompt is any statement about the food that would affect the student's choice)

Y Yes (1)

No (0)

Does the line have a clear traffic pattern?

Y Yes (1)

O No (0)

How would you rate the level of congestion within the line?

\begin{tabular}{|l|l|l|l|l|l|} 
& $\begin{array}{l}\text { No Congestion } \\
(2)\end{array}$ & $\begin{array}{l}\text { Slightly } \\
\text { Congested (1) }\end{array}$ & Neutral (1) & Congested (0) & $\begin{array}{l}\text { Very } \\
\text { Congested (0) }\end{array}$ \\
\hline $\begin{array}{l}\text { Level of } \\
\text { Congestion (1) }\end{array}$ & 0 & 0 & 0 & 0 & 0 \\
\hline
\end{tabular}

Did you detect any negative odor?

Y Yes (0)

No (1)

How would you rate the level of the food preparation smell?

\begin{tabular}{|l|l|l|l|l|l|} 
& No Smell (2) & Slight Smell (1) & Neutral (1) & $\begin{array}{l}\text { Favorable } \\
\text { Smell (0) }\end{array}$ & $\begin{array}{l}\text { Very Favorable } \\
\text { Smell (0) }\end{array}$ \\
\hline $\begin{array}{l}\text { Level of Smell } \\
(1)\end{array}$ & 0 & 0 & 0 & 0 & 0 \\
\hline
\end{tabular}

How would you rate the noise level within the area?

\begin{tabular}{|l|l|l|l|l|l|}
\hline & No/Low (2) & $\begin{array}{l}\text { Low to } \\
\text { Medium (1) }\end{array}$ & Medium (1) & Loud (0) & Very Loud (0) \\
\hline Noise Level (1) & 0 & 0 & 0 & 0 & 0 \\
\hline
\end{tabular}


How would you rate the level of lighting within the area?

\begin{tabular}{|l|l|l|l|l|l|}
\hline & No/Low (2) & $\begin{array}{l}\text { Low/Medium } \\
(1)\end{array}$ & Medium (1) & Bright (0) & Very Bright (0) \\
\hline $\begin{array}{l}\text { Lighting Level } \\
(1)\end{array}$ & 0 & 0 & 0 & 0 & 0 \\
\hline
\end{tabular}

Are there "healthy" posters or signage within the area? (healthy defined as nutritional or promoting a healthy lifestyle)

Y Yes (1)

O No (0)

Food appearance?

\begin{tabular}{|l|l|l|l|l|l|} 
& Poor (0) & $\begin{array}{l}\text { Low to } \\
\text { Moderate (1) }\end{array}$ & Moderate (1) & Appealing (2) & $\begin{array}{l}\text { Very Appealing } \\
(2)\end{array}$ \\
\hline $\begin{array}{l}\text { Food } \\
\text { Appearance } \\
\text { Rating (1) }\end{array}$ & 0 & 0 & 0 & 0 & 0 \\
\hline
\end{tabular}

Is fresh fruit available in more than one place?

Y Yes (1)

No (0)

Where is the fresh fruit displayed? (Check all that apply)

At the beginning of the line (1)

At the end of the line (0)

In another area of the line (0)

How is the fresh fruit displayed?

Ottractive bowls (1)

Stainless steel containers (0)

Clear plastic bins (0)

O Other (0)

Are fresh vegetables available in more than one place?

O Yes (1)

O No (0) 
Where are the fresh vegetables displayed within in the line?

At the beginning of the line (1)

At the end of the line (0)

In another area of the line (0)

How are the fresh vegetables displayed?

O In attractive bowls (1)

In stainless steel containers (0)

In clear plastic bins (0)

Other (0)

Are the fresh fruit and vegetables easy to access?

Y Yes (1)

O No (0)

Are the students greeted by the school staff as they enter the serving area?

Y Yes (1)

No (0)

Is the staff cheerful?

Y Yes (1)

O No (0)

Are the students prompted by the staff to take fresh fruit?

Yes (1)

O No (0)

Are the students prompted by the staff to take fresh vegetables?

Yes (1)

No (0)

Is the area where the hot food is being served kept clean and free from spills?

O Yes (1)

No (0)

Does the line have a clear traffic pattern?

Y Yes (1)

No (0) 
How would you rate the level of congestion within the line?

\begin{tabular}{|l|l|l|l|l|l|} 
& $\begin{array}{l}\text { No Congestion } \\
(2)\end{array}$ & $\begin{array}{l}\text { Slightly } \\
\text { Congested (1) }\end{array}$ & Neutral (1) & Congested (0) & $\begin{array}{l}\text { Very } \\
\text { Congested (0) }\end{array}$ \\
\hline $\begin{array}{l}\text { Level of } \\
\text { Congestion (1) }\end{array}$ & 0 & 0 & 0 & 0 & 0 \\
\hline
\end{tabular}

How would you rate the noise level within the area?

\begin{tabular}{|l|l|l|l|l|l|}
\hline & No/Low (2) & $\begin{array}{l}\text { Low to } \\
\text { Medium (1) }\end{array}$ & Medium (1) & Loud (0) & Very Loud (0) \\
\hline Noise Level (1) & 0 & 0 & 0 & 0 & 0 \\
\hline
\end{tabular}

How would you rate the level of lighting within the area?

\begin{tabular}{|l|l|l|l|l|l|} 
& No/Low (0) & $\begin{array}{l}\text { Low to } \\
\text { Medium (1) }\end{array}$ & Medium (1) & Bright (2) & Very Bright (2) \\
\hline $\begin{array}{l}\text { Level of } \\
\text { Lighting (1) }\end{array}$ & 0 & 0 & 0 & 0 & 0 \\
\hline
\end{tabular}

Are there "healthy" posters or signage within the area? (healthy defined as nutritional or promoting a healthy lifestyle)

O Yes (1)

No (0)

Food appearance?

\begin{tabular}{|l|l|l|l|l|l|}
\hline & Poor (1) & $\begin{array}{l}\text { Low to } \\
\text { Moderate (2) }\end{array}$ & Moderate (3) & Appealing (4) & $\begin{array}{l}\text { Very Appealing } \\
\text { (5) }\end{array}$ \\
\hline $\begin{array}{l}\text { Food } \\
\text { Appearance } \\
\text { Rating (1) }\end{array}$ & 0 & 0 & 0 & 0 & 0 \\
\hline
\end{tabular}

Is fresh fruit available in more than one place?

O Yes (1)

O No (0) 
Where is the fresh fruit displayed within the line?

At the beginning of the line (1)

At the end of the line (0)

$O$ In another area of the line (0)

How is the fresh fruit displayed?

O In attractive bowls (1)

In stainless steel containers (0)

In plastic bins (0)

Other (0)

Are fresh vegetables available in more than one place?

Y Yes (1)

O No (0)

Where are the fresh vegetables displayed within the line?

At the beginning of the line (1)

At the end of the line (0)

In another area of the line (0)

Are fresh fruit and vegetables easy to access?

O Yes (1)

O No (0)

Are the students greeted by staff as they enter the serving area?

Y Yes (1)

O No (0)

Is the staff cheerful?

Y Yes (1)

No (0)

Are the students prompted by the staff to take fresh fruit?

Y Yes (1)

No (0)

Are the students prompted by the staff to take fresh vegetables?

Y Yes (1)

No (0) 
Is the area where the cold food is being served kept clean and free from spills?

Y Yes (1)

No (0)

Does the line have a clear traffic pattern?

O Yes (1)

No (0)

How would you rate the level of congestion within the line?

\begin{tabular}{|l|l|l|l|l|l|} 
& $\begin{array}{l}\text { No Congestion } \\
(2)\end{array}$ & $\begin{array}{l}\text { Slightly } \\
\text { Congested (1) }\end{array}$ & Neutral (1) & Congested (0) & $\begin{array}{l}\text { Very } \\
\text { Congested (0) }\end{array}$ \\
\hline $\begin{array}{l}\text { Level of } \\
\text { Congestion (1) }\end{array}$ & 0 & 0 & 0 & 0 & 0 \\
\hline
\end{tabular}

How would you rate the noise level within the area?

\begin{tabular}{|l|l|l|l|l|l|} 
& No/Low (2) & $\begin{array}{l}\text { Low to } \\
\text { Medium (1) }\end{array}$ & Medium (1) & Loud (0) & Very Loud (0) \\
\hline Noise Level (1) & 0 & 0 & 0 & 0 & 0 \\
\hline
\end{tabular}

How would you rate the level of lighting within the area?

\begin{tabular}{|l|l|l|l|l|l|} 
& No/Low (1) & $\begin{array}{l}\text { Low to } \\
\text { Medium (2) }\end{array}$ & Medium (3) & Bright (4) & Very Bright (5) \\
\hline $\begin{array}{l}\text { Level of } \\
\text { Lighting (1) }\end{array}$ & 0 & 0 & 0 & 0 & 0 \\
\hline
\end{tabular}

Is there a salad bar?

O Yes (1)

No (0)

Is the salad bar easily accessible?

O Yes (1)

O No (0) 
Are the self-serve tongs/scoops easy to use?

Y Yes (1)

No (0)

Is the salad bar kept clean and free from spills?

O Yes (1)

No $(0)$

Are there enough serving tongs/scoops to use?

O Yes (1)

O No (0)

Is there a clear traffic pattern to the salad bar?

Y Yes (1)

No (0)

How would you rate the level of congestion within the area?

\begin{tabular}{|l|l|l|l|l|l|} 
& $\begin{array}{l}\text { No Congestion } \\
(2)\end{array}$ & $\begin{array}{l}\text { Slightly } \\
\text { Congested (1) }\end{array}$ & Neutral (1) & Congested (0) & $\begin{array}{l}\text { Very } \\
\text { Congested (0) }\end{array}$ \\
\hline $\begin{array}{l}\text { Level of } \\
\text { Congestion (1) }\end{array}$ & 0 & 0 & 0 & 0 & 0 \\
\hline
\end{tabular}

How would you rate the level of lighting within the area?

\begin{tabular}{|l|l|l|l|l|l|}
\hline & No/Low (0) & $\begin{array}{l}\text { Low to } \\
\text { Medium (1) }\end{array}$ & Medium (1) & Bright (2) & Very Bright (2) \\
\hline $\begin{array}{l}\text { Level of } \\
\text { Lighting (1) }\end{array}$ & O & 0 & 0 & 0 & 0 \\
\hline
\end{tabular}

Are there posters or signage promoting white milk consumption?

Y Yes (1)

O No (0)

Is the beverage container filled with at least $50 \%$ white milk?

O Yes (1)

No (0) 
Is the white milk easily accessible?

Yes (1)

Is there a clear traffic pattern to the milk?

Y Yes (1)

O No (0)

As the students approach the beverage container, is the white milk offered first?

Y Yes (1)

O No (0)

How would you rate the level of congestion within the area?

\begin{tabular}{|l|l|l|l|l|l|}
\hline & $\begin{array}{l}\text { No Congestion } \\
(2)\end{array}$ & $\begin{array}{l}\text { Slightly } \\
\text { Congested (1) }\end{array}$ & Neutral (1) & Congested (0) & $\begin{array}{l}\text { Very } \\
\text { Congested (0) }\end{array}$ \\
\hline $\begin{array}{l}\text { Level of } \\
\text { Congestion (1) }\end{array}$ & 0 & 0 & 0 & 0 & 0 \\
\hline
\end{tabular}

Are there fresh fruit or vegetables offered at the payment station?

Y Yes (1)

No (0)

Is there a clear traffic pattern to the payment station?

O Yes (1)

O No (0)

How would you rate the level of congestion within the area?

\begin{tabular}{|l|l|l|l|l|l|} 
& $\begin{array}{l}\text { No Congestion } \\
(2)\end{array}$ & $\begin{array}{l}\text { Slightly } \\
\text { Congested (1) }\end{array}$ & Neutral (1) & Congested (0) & $\begin{array}{l}\text { Very } \\
\text { Congested (0) }\end{array}$ \\
\hline $\begin{array}{l}\text { Level of } \\
\text { Congestion (1) }\end{array}$ & 0 & 0 & 0 & 0 & 0 \\
\hline
\end{tabular}

Is the payment method efficient?

Y Yes (1)

O No (0) 
Are there "healthy" posters or signage within the area? (healthy defined as nutritional or promoting a healthy lifestyle)

Y Yes (1)

No (0)

Is tomorrow's lunch menu posted?

Y Yes (1)

O No (0)

Is the menu clear and neat?

Y Yes (1)

No (0)

Is there a clear traffic pattern into the dining area?

Y Yes (1)

No (0)

How would you rate the level of congestion?

\begin{tabular}{|l|l|l|l|l|l|} 
& $\begin{array}{l}\text { No Congestion } \\
(2)\end{array}$ & $\begin{array}{l}\text { Slightly } \\
\text { Congested (1) }\end{array}$ & Neutral (1) & Congested (0) & $\begin{array}{l}\text { Very } \\
\text { Congested (0) }\end{array}$ \\
\hline $\begin{array}{l}\text { Level of } \\
\text { Congestion (1) }\end{array}$ & 0 & 0 & 0 & 0 & 0 \\
\hline
\end{tabular}

How would you rate the level of lighting within the area?

\begin{tabular}{|l|l|l|l|l|l|}
\hline & No/Low (0) & $\begin{array}{l}\text { Low to } \\
\text { Medium (1) }\end{array}$ & Medium (1) & Bright (2) & Very Bright (2) \\
\hline $\begin{array}{l}\text { Lighting Level } \\
(1)\end{array}$ & 0 & 0 & 0 & 0 & 0 \\
\hline
\end{tabular}

How would you rate the noise level within the area?

\begin{tabular}{|l|l|l|l|l|l|}
\hline & No/Low (2) & $\begin{array}{l}\text { Low to } \\
\text { Medium (1) }\end{array}$ & Medium (1) & Loud (0) & Very Loud (0) \\
\hline Noise Level (1) & 0 & 0 & 0 & 0 & 0 \\
\hline
\end{tabular}


Do you detect any negative smell?

O Yes (0)

No (1)

How would you rate the level of food smell within the area?

\begin{tabular}{|l|l|l|l|l|l|}
\hline & No Smell (1) & Slight Smell (2) & Neutral (3) & Favorable (4) & $\begin{array}{l}\text { Very Favorable } \\
(5)\end{array}$ \\
\hline $\begin{array}{l}\text { Level of Smell } \\
(1)\end{array}$ & 0 & 0 & 0 & 0 & 0 \\
\hline
\end{tabular}

Is the garbage area kept clean?

Y Yes (1)

O No (0)

Did you notice any food waste?

O Yes (0)

No (1)

If yes, then what percentage of food was wasted?

O $0-25 \%$ (1)

O $26 \%-50 \%(2)$

O $51 \%-75 \%(3)$

O $76 \%-100 \%(4)$

Is there recycling available?

Y Yes (1)

No (0)

Is there teaching staff present?

Y Yes (1)

No (0)

Is there administration staff present?

O Yes (1)

No (0)

Do the students have an adequate amount of time to eat their lunch? (i.e. 20 minutes)

Y Yes (1)

No (0) 
Is there a grab and go option?

O Yes (1)

O No (0)

Is there a lunch menu posted within the area?

O Yes (1)

O No (0)

Is the menu clear and neat?

O Yes (1)

O No (0)

Food Appearance?

\begin{tabular}{|l|l|l|l|l|l|}
\hline & Poor (0) & $\begin{array}{l}\text { Low to } \\
\text { Moderate (1) }\end{array}$ & Moderate (1) & Appealing (2) & $\begin{array}{l}\text { Very Appealing } \\
\text { (2) }\end{array}$ \\
\hline $\begin{array}{l}\text { Click to write } \\
\text { Statement 1 } \\
(1)\end{array}$ & 0 & 0 & 0 & 0 & 0 \\
\hline
\end{tabular}

Is fresh fruit available in more than one place?

Y Yes (1)

No (0)

Where is fresh fruit displayed?

At the beginning of the line (1)

At the end of the line (0)

O In another area of the line (0)

How is the fresh fruit displayed?

$O$ In attractive bowls (1)

In stainless steel bins (0)

In clear plastic containers (0)

Other (0)

Are fresh vegetables available in more than one place?

Y Yes (1)

No (0) 
Where are the fresh vegetables displayed?

At the beginning of the line (1)

At the end of the line (0)

O In another area of the line (0)

How are the fresh vegetables displayed?

O In attractive bowls (1)

In stainless steel containers (0)

In clear plastic bins (0)

Other (0)

Are fresh fruit and vegetables easy to access?

Y Yes (1)

O No (0)

Is the beverage container filled with at least $50 \%$ white milk?

Y Yes (1)

No (0)

As the students approach the beverage container, is the white milk offered first?

O Yes (1)

No (0)

Is there a clear traffic pattern for the grab and go option?

Yes (1)

No (0)

How would you rate the level of congestion within the area?

\begin{tabular}{|l|l|l|l|l|l|} 
& $\begin{array}{l}\text { No Congestion } \\
(2)\end{array}$ & $\begin{array}{l}\text { Slightly } \\
\text { Congested (1) }\end{array}$ & Neutral (1) & Congested (0) & $\begin{array}{l}\text { Very } \\
\text { Congested (0) }\end{array}$ \\
\hline $\begin{array}{l}\text { Level of } \\
\text { Congestion (1) }\end{array}$ & 0 & 0 & 0 & 0 & 0 \\
\hline
\end{tabular}

Are the students greeted by staff?

Y Yes (1)

O No (0) 
Is the staff cheerful?

Y Yes (1)

No (0)

Are the students prompted by the staff to take fresh fruit?

O Yes (1)

No (0)

Are the students prompted by the staff to take fresh vegetables?

Y Yes (1)

O No (0)

Is the serving area clean and free form any spills?

O Yes (1)

No (0)

How would you rate the lighting level?

\begin{tabular}{|l|l|l|l|l|l|}
\hline & No/Low (0) & $\begin{array}{l}\text { Low to } \\
\text { Medium (1) }\end{array}$ & Medium (1) & Bright (2) & Very Bright (2) \\
\hline $\begin{array}{l}\text { Lighting Level } \\
(1)\end{array}$ & 0 & 0 & 0 & 0 & 0 \\
\hline
\end{tabular}

How would you rate the noise level?

\begin{tabular}{|l|l|l|l|l|l|}
\hline & No/Low (2) & $\begin{array}{l}\text { Low to } \\
\text { Medium (1) }\end{array}$ & Medium (1) & Loud (0) & Very Loud (0) \\
\hline Noise Level (1) & 0 & 0 & 0 & 0 & 0 \\
\hline
\end{tabular}

Is the payment method efficient?

O Yes (1)

No (0) 
Appendix B: Video Assessment Questions

Rate the Exterior Environment in the following categories

Congestion

Very Congested Congested Neutral Slightly Congested No Congestion

Wait time

$>3$ minutes $\quad>2$ minutes $>1$ minute $>30$ seconds No Wait Time

Traffic Pattern

Not Efficient

Slightly Efficient

Neutral

Efficient

Very Efficient

Rate the Serving Environment in the following categories

Congestion

Very Congested Congested Neutral Slightly Congested No Congestion

Wait time

$>3$ minutes

$>2$ minutes

$>1$ minute $\quad>30$ seconds

No Wait Time

Traffic Pattern

Not Efficient

Slightly Efficient

Neutral

Efficient

Very Efficient

Rate the Dining Environment in the following categories

Congestion

Very Congested Congested Neutral Slightly Congested No Congestion

Traffic Pattern

Not Efficient

Slightly Efficient

Neutral

Efficient

Very Efficient

Amount of time to eat their lunch

$<16$ minutes

17 minutes

18 minutes

19 minutes

20 minutes 
Rate the Grab and Go Environment in the Following Categories

Congestion

Very Congested Congested Neutral Slightly Congested No Congestion

Traffic Pattern

Not Efficient

Slightly Efficient

Neutral

Efficient

Very Efficient

Wait time

$>3$ minutes

$>2$ minutes

$>1$ minute $\quad>30$ seconds

No Wait Time 


\section{Appendix C: Post-Site-Visit Questions}

1. In your opinion, what are 3 areas that were done well in this cafeteria? (strengths)

2. In your opinion, what are 3 areas that need improvement in this cafeteria? (weaknesses)

3. Did you notice any unique/specific characteristics that describe this high school in particular? 
Appendix D: Site \#1 Recommendation Report

(Serving)

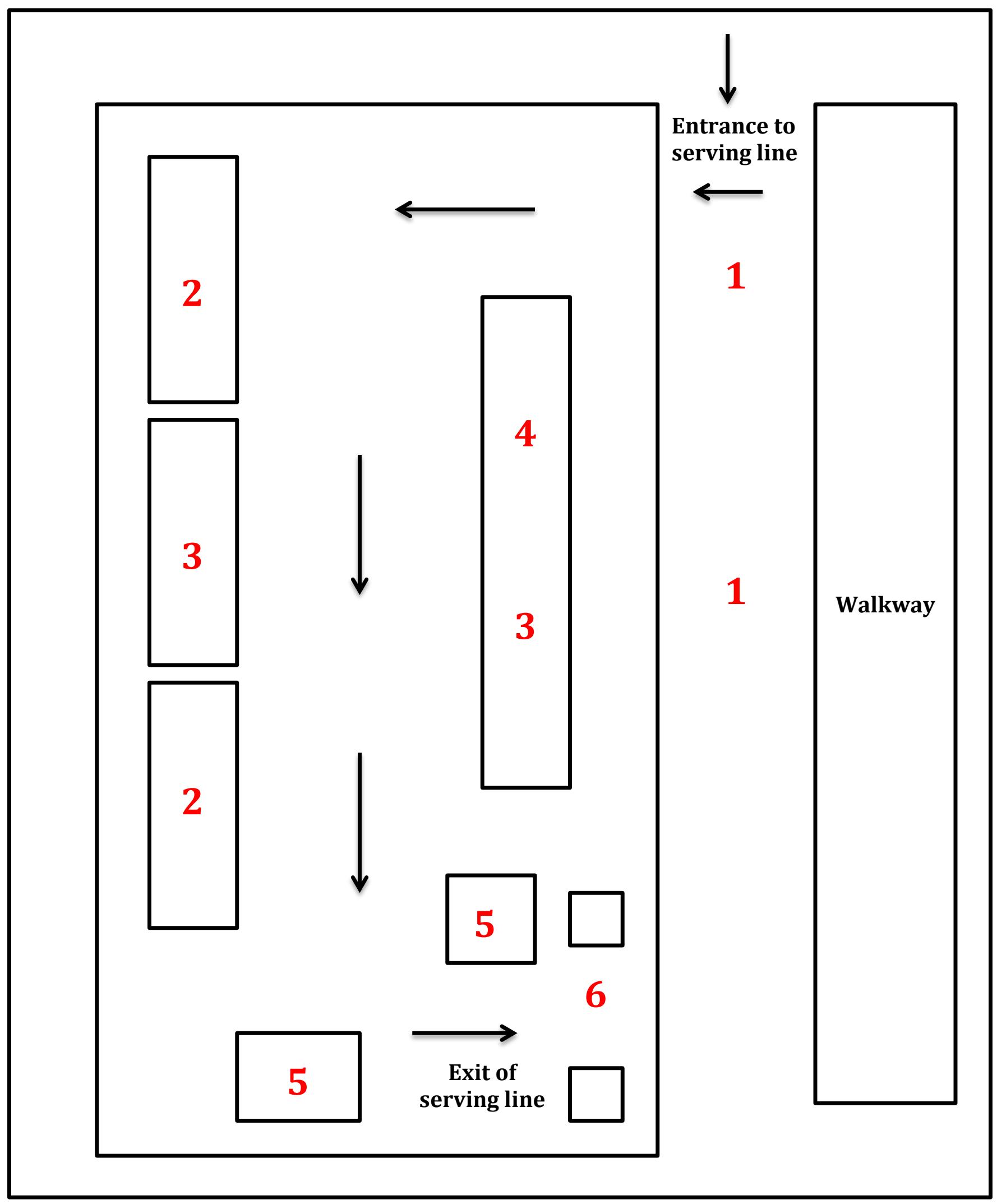


Appendix D: Site \#1 Recommendation Report

(Dining \& Grab and Go)

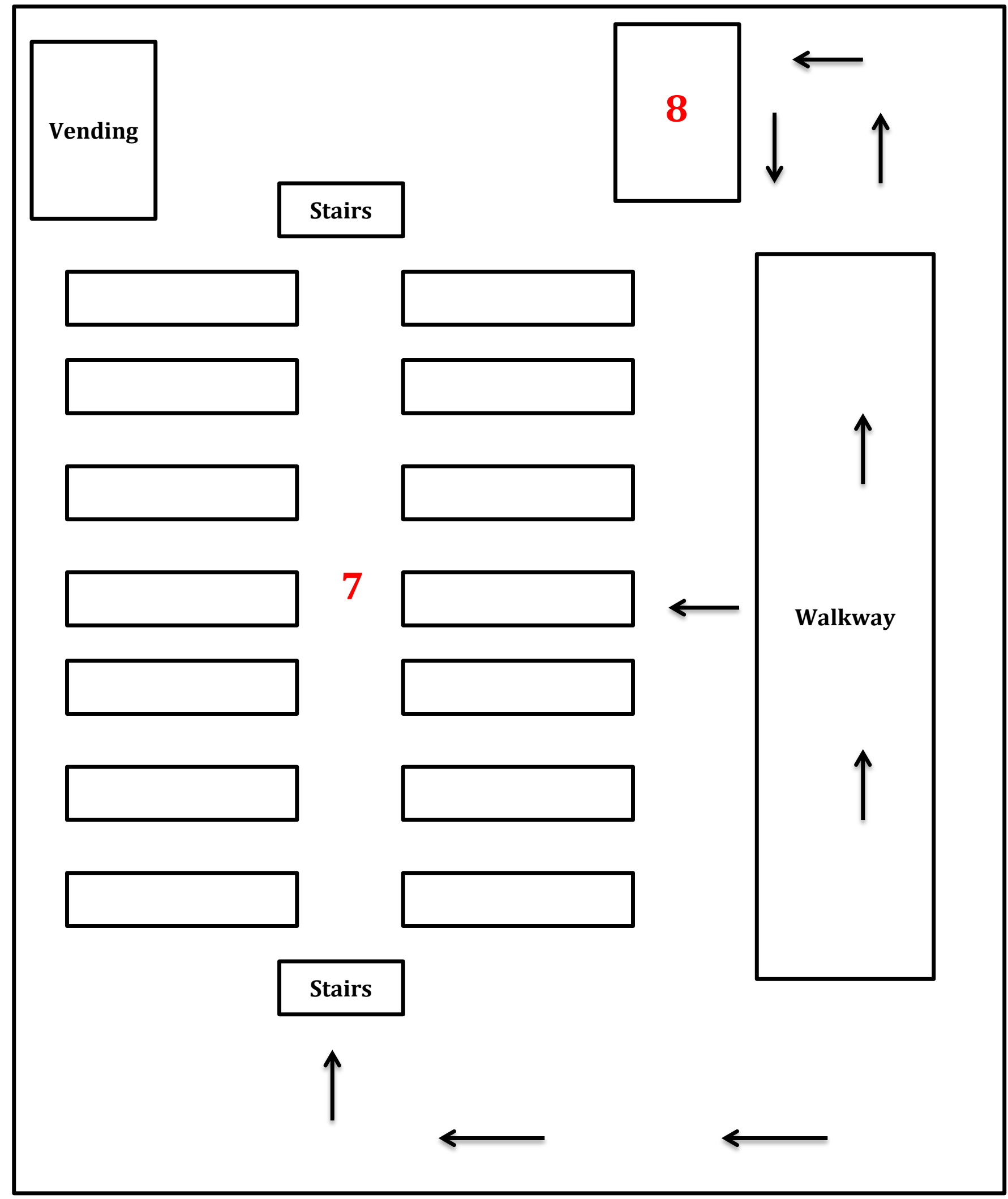




\section{Interpretation of Recommendations}

1. Exterior = Place healthy signage within the exterior environment.

2. Serving Area: Hot = Express importance of student and staff interaction. Have staff greet students in a friendly manner.

3. Serving Area: Cold = Present the fresh fruit in attractive bowls within the salad bar area.

4. Salad Bar $=$ Offer pre-cut and pre-packaged fresh vegetables

5. Beverage Area $=$ Place low-fat white milk first in the beverage container

6. Payment Station $=$ Place fresh fruit in an attractive bowl at payment station

7. Dining Area $=$ Provide recycling bins to the students in dining area

8. Grab and $\mathrm{Go}=$ Use clear bags for the Grab and Go lunches

*Arrows show how the students move through the line 
Appendix E: Site \#2 Recommendation Report

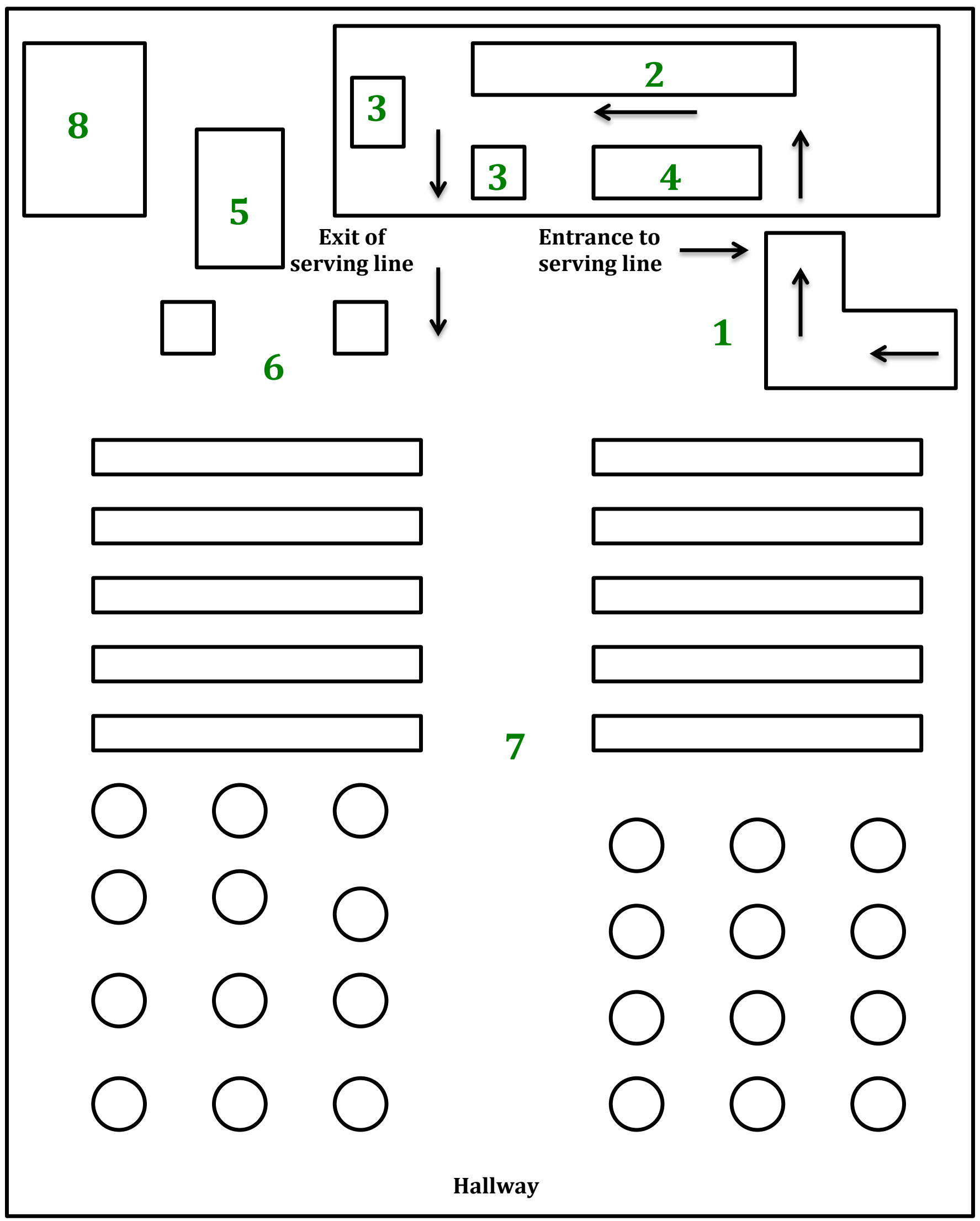




\section{Interpretation of Recommendations}

1. Exterior $=$ Place healthy signage within the exterior environment.

2. Serving Area: Hot = Express importance of student and staff interaction. Have staff greet students in a friendly manner.

3. Serving Area: Cold = Present the fresh fruit in attractive bowls within the salad bar area.

4. Salad Bar $=$ Provide more serving utensils

5. Beverage Area $=$ Place low-fat white milk first in the beverage container

6. Payment Station $=$ Place fresh fruit in an attractive bowl at payment station

7. Dining Area $=$ Provide recycling bins to the students in dining area

8. Grab and $\mathrm{Go}=$ Post a lunch menu within the area

*Arrows show how the students move through the line 
Appendix F: Site \#3 Recommendation Report

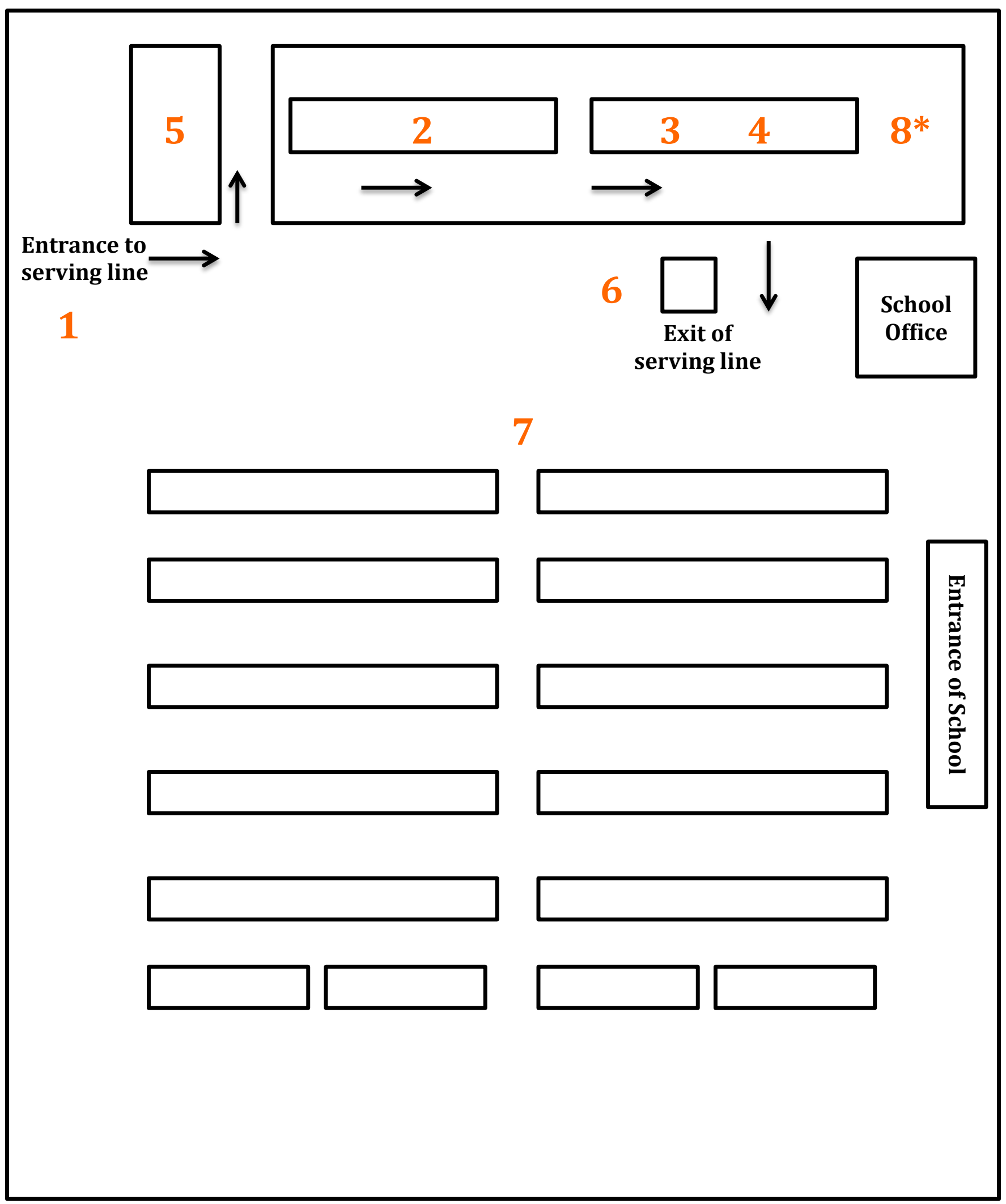




\section{Interpretation of Recommendations}

1. Exterior = Place healthy signage within the exterior environment.

2. Serving Area: Hot = Keep area clean and free from spills

3.Serving Area: Cold = Present the fresh fruit in attractive bowls within the salad bar area.

4.Salad Bar $=$ Offer pre-cut and pre-packaged fresh vegetables

5. Beverage Area = Place low-fat white milk first in the beverage container

6. Payment Station = Place fresh fruit in an attractive bowl at payment station

7. Dining Area $=$ Provide recycling bins for students in the dining area

8. Grab and Go = Implement $\mathrm{a}$ Grab and Go option*

*Arrows show how the students move through the line 